\title{
An electrospray chemical ionization source for real-time measurement of atmospheric organic and inorganic vapors
}

\author{
Yue Zhao $^{1}$, Jeremy K. Chan ${ }^{1,2}$, Felipe D. Lopez-Hilfiker ${ }^{1,3}$, Megan A. McKeown ${ }^{1}$, Emma L. D'Ambro' ${ }^{1,4}$, \\ Jay G. Slowik ${ }^{3}$, Jeffrey A. Riffell ${ }^{2}$, and Joel A. Thornton ${ }^{1,4}$ \\ ${ }^{1}$ Department of Atmospheric Sciences, University of Washington, Seattle, WA 98195, USA \\ ${ }^{2}$ Department of Biology, University of Washington, Seattle, WA 98195, USA \\ ${ }^{3}$ Laboratory of Atmospheric Chemistry, Paul Scherrer Institute, 5232 Villigen, Switzerland \\ ${ }^{4}$ Department of Chemistry, University of Washington, Seattle, WA 98195, USA
}

Correspondence to: Joel A. Thornton (thornton@atmos.washington.edu) and Felipe D. Lopez-Hilfiker (felipe.lopez@psi.ch)

Received: 24 March 2017 - Discussion started: 30 March 2017

Revised: 17 July 2017 - Accepted: 9 August 2017 - Published: 4 October 2017

\begin{abstract}
We present an electrospray ion source coupled to an orthogonal continuous-flow atmospheric pressure chemical ionization region. The source can generate intense and stable currents of several specific reagent ions using a range of salt solutions prepared in methanol, thereby providing both an alternative to more common radioactive ion sources and allowing for the generation of reagent ions that are not available in current chemical ionization mass spectrometry (CIMS) techniques, such as alkaline cations. We couple the orthogonal electrospray chemical ionization (ESCI) source to a high-resolution time-of-flight mass spectrometer (HRToF-MS), and assess instrument performance through calibrations using nitric acid $\left(\mathrm{HNO}_{3}\right)$, formic acid $(\mathrm{HCOOH})$, and isoprene epoxydiol (trans- $\beta$-IEPOX) gas standards, and through measurements of oxidized organic compounds formed from ozonolysis of $\alpha$-pinene in a continuous-flow reaction chamber. When using iodide as the reagent ion, the HR-ToF-ESCIMS prototype has a sensitivity of $11,2.4$, and $10 \mathrm{cps} \mathrm{pptv}^{-1}$ per million counts per second (cps) of reagent ions and a detection limit ( $3 \sigma, 5 \mathrm{~s}$ averaging) of 4.9, 12.5, and $1.4 \mathrm{pptv}$ to $\mathrm{HNO}_{3}, \mathrm{HCOOH}$, and IEPOX, respectively. These values are comparable to those obtained using an iodide-adduct HR-ToF-CIMS with a radioactive ion source and low-pressure ion-molecule reaction region. Applications to the $\alpha$-pinene ozonolysis system demonstrates that HRToF-ESCIMS can generate multiple reagent ions (e.g., $\mathrm{I}^{-}$, $\mathrm{NO}_{3}^{-}$, acetate, $\mathrm{Li}^{+}, \mathrm{Na}^{+}, \mathrm{K}^{+}$, and $\mathrm{NH}_{4}^{+}$) having different selectivity to provide a comprehensive molecular description of a complex organic system.
\end{abstract}

\section{Introduction}

The Earth's atmosphere contains thousands of inorganic and organic species that, through complex free radical and multiphase chemistry, play a vital role in air quality and climate change (Finlayson-Pitts and Pitts, 2000; Seinfeld and Pandis, 2006; Goldstein and Galbally, 2007). Characterizing the identity and abundance of many of these species in the atmosphere is essential for understanding their atmospheric processes and subsequent environmental and climate impacts. As a result, there is a critical interest in the development and application of the state-of-art analytical instruments for the analysis of atmospheric composition (Noziere et al., 2015).

As a sensitive, selective, and soft-ionization measurement technique, chemical ionization mass spectrometry (CIMS) has received significant use in the real-time in situ measurement of atmospheric trace species (Huey et al., 1995; Fortner et al., 2004; Hearn and Smith, 2004; Smith et al., 2004; Crounse et al., 2006; Huey, 2007; Veres et al., 2008; Kercher et al., 2009; Zhao et al., 2010). The recent coupling of chemical ionization to high-resolution time-of-flight mass spectrometers (HR-ToF-MS) enables the simultaneous determination of the abundance and molecular composition of a wide array of atmospheric inorganic and organic compounds with fast time response and high sensitivity (Junninen et al., 2010; Bertram et al., 2011; Yatavelli et al., 2012; Aljawhary et al., 2013; Lee et al., 2014; Lopez-Hilfiker et al., 2014, 2016a; Brophy and Farmer, 2015, 2016; Yuan et al., 2016). The use of HR-ToF-CIMS has allowed for groundbreaking progress in atmospheric organic chemistry, such as the observation of 
highly oxygenated molecules (HOMs) formed by monoterpene oxidation (Ehn et al., 2014; Jokinen et al., 2015; Berndt et al., 2016; Lee et al., 2016). Very recently, a newly developed proton-transfer reaction (PTR) time-of-flight instrument (PTR-3) has enabled sensitive detection of a wide range of organic compounds including HOMs (Breitenlechner et al., 2017).

In CIMS, the analyte molecule reacts with a specific reagent ion via one or more mechanisms, including ligand switching reaction forming an ion-molecule adduct (Huey et al., 1995; Kercher et al., 2009; Aljawhary et al., 2013; Lee et al., 2014; Brophy and Farmer, 2015, 2016), proton addition (abstraction) forming a protonated (de-protonated) ion (Nowak et al., 2002; Veres et al., 2008; Yatavelli et al., 2012; Aljawhary et al., 2013; Brophy and Farmer, 2015, 2016; Yuan et al., 2016), or by direct charge transfer forming a molecular ion (Huey et al., 1995; Kim et al., 2016). The reagent ions used mainly include $\mathrm{I}^{-}, \mathrm{NO}_{3}^{-}$, acetate, $\mathrm{CF}_{3} \mathrm{O}^{-}$, and $\mathrm{SF}_{6}^{-}$for negative ion CIMS, and $\mathrm{H}_{3} \mathrm{O}^{+}, \mathrm{NO}^{+}$, protonated ethanol, and benzene cation for positive ion CIMS. Choosing an appropriate reagent ion is essential for the comprehensive characterization of a specific class of molecules while having selectivity to avoid unnecessary congestion of the mass spectrum with unwanted components. For example, previous studies using $\mathrm{NO}_{3}^{-}$CIMS have reported a very low yield of HOMs from $\mathrm{OH}$ oxidation of monoterpene (Jokinen et al., 2015). However, a recent study using acetate CIMS found a significantly higher HOMs yields from the same system (Berndt et al., 2016). The reason for this difference is presumably a lower sensitivity of $\mathrm{NO}_{3}^{-}$to $\mathrm{HOMs}$ formed in $\mathrm{OH}$ oxidation of monoterpene than that of acetate (Berndt et al., 2016). On the other hand, many atmospheric organic systems consist of a wide range of organic compounds with different functionality and polarity. Therefore, multiple complementary ionization schemes are needed to obtain a broad view of these systems (Aljawhary et al., 2013; Praplan et al., 2015).

Some advantages of CIMS are that it is direct, online, reproducible, and inherently quantitative in that the kinetic theory of gases allows a robust upper limit ionization efficiency, and thus instrument response, to be calculated knowing only the pressure and interaction time of reagent ions and analyte molecules. However, the need for gas-phase reagent ions limits the suite of usable reagent ions to those for which a safe and stable gas-phase precursor exists and which produce the desired reagent ion cleanly at a high yield when ionized. As such, certain reagent ions such as metal cations (e.g., $\mathrm{Li}^{+}$, $\mathrm{Na}^{+}$, and $\mathrm{K}^{+}$) and $\mathrm{NH}_{4}^{+}$, which are commonly used for detection of atmospheric organic compounds in offline techniques like electrospray ionization (ESI)-MS (Nizkorodov et al., 2011; Laskin et al., 2012; Witkowski and Gierczak, 2013), have remained largely unavailable for CIMS (Fujii et al., 2001). Compared to $\mathrm{I}^{-}, \mathrm{NO}_{3}^{-}$, and acetate, which are generally more sensitive to more oxygenated organic compounds than to less oxygenated ones (Aljawhary et al., 2013; Lee et al., 2014; Hyttinen et al., 2015; Iyer et al., 2016; Berndt et al., 2016), these metal cations are expected to be able to sensitively detect both less oxygenated (e.g., compounds containing only carbonyl groups) and highly oxygenated multi-functional organic species (Gao et al., 2010; Nguyen et al., 2010; Nizkorodov et al., 2011; Laskin et al., 2012; Witkowski and Gierczak, 2013; Zhao et al., 2015, 2016; Tu et al., 2016; Zhang et al., 2017), and to form more strongly bound ion adducts. In addition, at present most CIMS techniques use a radioactive ion source such as ${ }^{210} \mathrm{Po}$ to produce the reagent ions, although more recently some utilize X-ray radiation, electrical discharge (Hirokawa et al., 2009; Yuan et al., 2016), or electron impact (Inomata and Hirokawa, 2017). Safety regulations for the transport and use of radioactive materials may limit the deployment of the instrument with a radioactive ion source in the field, while other methods may be less intense or lead to higher backgrounds.

We have developed a non-radioactive reagent ion source that deploys a custom-built electrospray setup within an atmospheric pressure orthogonal ion-molecule reaction (IMR) chamber. The design of the IMR region is similar to that of the Cluster-CIMS developed by Eisele and coworkers (Zhao et al., 2010). The electrospray chemical ionization (ESCI) source is coupled to a HR-ToF-MS for characterization. We present the design and discuss the parameters most important for optimal performance of the ESCI source. Then, we assess its performance using the measurement of formic acid, IEPOX, nitric acid, and organic mixtures formed by ozonolysis of $\alpha$-pinene in a continuous-flow reaction chamber. Our results demonstrate that the ESCI source provides a potential alternative to radioactive and X-ray ion source and opens a new avenue for the generation of reagent ions such as $\mathrm{Li}^{+}$, $\mathrm{Na}^{+}, \mathrm{K}^{+}$, and so on that were previously unavailable for CIMS.

\section{Experimental section}

\subsection{Instrument description}

A schematic of the ESCI module is shown in Fig. 1. The electrospray setup contains a $15 \mu \mathrm{m}$ inner diameter (ID) fused silica spray needle $\left(\right.$ PicoTip $^{\mathrm{TM}}$ ) mounted within a cylindrical evaporation chamber through which a flow of ultra-high purity (UHP) $\mathrm{N}_{2}$ (referred to as the ion source flow) is passed to aid in the evaporation of the spray droplets and to transport ions into the IMR. Several spray needle diameters were tried (from 8 to $30 \mu \mathrm{m}$ ), with the $15 \mu \mathrm{m}$ giving the best combination of longevity and ion intensity. The emitting end of the spray needle is located $4 \mathrm{~mm}$ from the distal wall of the evaporation chamber, which consists of a $13 \mathrm{~mm}$ ID stainless steel (SS) tube centered on a circular SS aperture having a $4 \mathrm{~mm}$ diameter. The aperture forms the entrance to the IMR, which is a portion of a $22 \mathrm{~mm}$ ID SS tube embedded in a Teflon block. The ion source flow enters the IMR through the aper- 


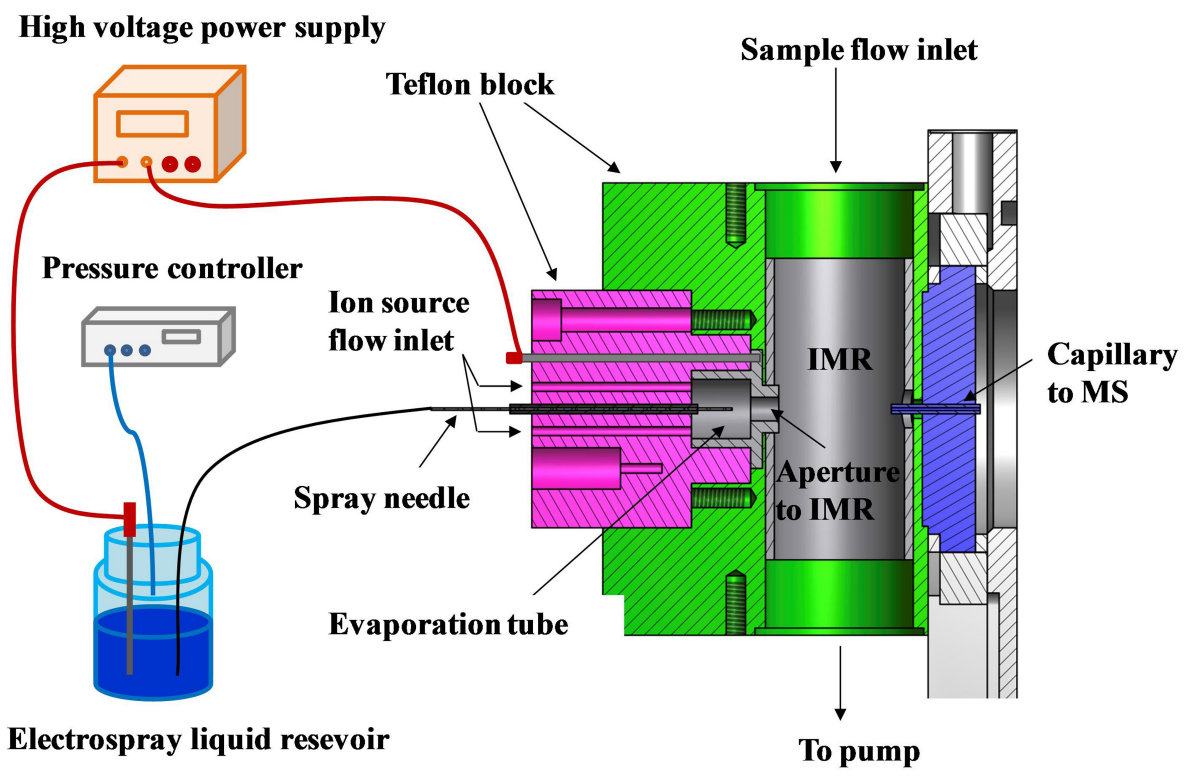

Figure 1. Schematic of the electrospray chemical ionization (ESCI) source module. Also shown are the orthogonal atmospheric pressure IMR and the entrance capillary serving as the atmospheric pressure interface between the IMR and the vacuum chamber of HR-ToF-MS. See text for detailed description of the source.

ture perpendicularly to the direction of a much larger sample flow, typically 10 to 20 standard liters per minute (standard $\mathrm{L} \mathrm{min}^{-1}$ ) drawn through the IMR by a dry scroll vacuum pump (IDP-3, Agilent Technologies). Preliminary fluid dynamic simulations suggest that the mixed sample and ion source flow in the IMR remains laminar when the ratio of the ion source flow to sample flow is $\leq 0.2$ and the overall Reynolds number for the sample flow is low (sample flow $<20$ standard $\mathrm{L} \mathrm{min}^{-1}$ ).

Ions are driven across the perpendicular sample flow to a SS capillary tube located on the opposite wall of the IMR by means of a $2-4 \mathrm{kV}$ potential between the evaporation region lens and the capillary tube. The SS capillary projects $3.5 \mathrm{~mm}$ into the IMR and acts as the atmospheric pressure interface between the IMR and the vacuum chamber of a commercial HR-ToF-MS (Tofwerk AG, Thun, Switzerland), effectively dropping the atmospheric pressure to 1.5 Torr in the first quadrupole of the MS, and resulting in a sample flow of $\sim 270 \mathrm{sccm}$ (standard cubic centimeters per minute) into the MS. The HR-ToF-MS and its data acquisition procedures have been described in detail previously (Junninen et al., 2010; Bertram et al., 2011; Lee et al., 2014). The evaporation tube, lens and IMR tube are electrically connected, while the mass spectrometer entrance capillary is electrically isolated from the IMR by a $\sim 1 \mathrm{~mm}$ thick jacket of Teflon.

During operation, a dilute salt solution $(500 \mathrm{ppm})$ in HPLC-grade methanol (MEOH) is biased at the reservoir to $\pm(2-5) \mathrm{kV}$ depending on the ion mode by connecting a stainless steel rod immersed into the solution to a high voltage power supply. At a given reservoir solution voltage $\left(V_{R}\right)$, the voltage applied to the evaporation tube and IMR $\left(V_{\mathrm{L}}\right)$ was carefully tuned to get the best ion signals $\left(S_{\max }\right)$, as well as the corresponding $V_{\mathrm{L}}$, referred to as $V_{\mathrm{L}}\left(\mathrm{S}_{\max }\right)$. In the $V_{\mathrm{R}}$ range of $2-5 \mathrm{kV}$, a larger $V_{\mathrm{R}}$ (with a larger $V_{\mathrm{L}}\left(\mathrm{S}_{\mathrm{max}}\right)$ ) gives a higher reagent ion signal. To obtain good ion signals, for most of the measurements performed in this study, $V_{R}$ values of $5 \mathrm{kV}$ (corresponding $V_{\mathrm{L}}\left(\mathrm{S}_{\max }\right)=2.8 \mathrm{kV}$ ) and $-5 \mathrm{kV}$ (corresponding $\left.V_{\mathrm{L}}\left(\mathrm{S}_{\max }\right)=-3.9 \mathrm{kV}\right)$ were used in the positive ion and negative ion modes, respectively. The reservoir is maintained at approximately 50 mbar above atmosphere using a commercial pressure controller (FLUIGENT, model MFCS-EZ) with 0.05 mbar precision. As a result, the salt solution is pushed through the fumed silica capillary tube to the spray needle at a flow rate less than $100 \mathrm{~nL} \mathrm{~min}^{-1}$ by the pressure in the reservoir bottle.

Under laminar flow conditions, the reaction time between reagent ions and sampled trace gases in the IMR is mainly determined by the electric field-induced drift velocity of the reagent ions. For instance, for two of the reagent ions used in this study, $\mathrm{NO}_{3}^{-}$and $\mathrm{Na}^{+}$, the ion-molecule reaction time (i.e., ion drift time) in the IMR is estimated to be $0.5-1$ and $0.4-0.7 \mathrm{~ms}$, respectively, with an ion mobility of $2.37 \mathrm{~cm}^{2} \mathrm{~s}^{-1} \mathrm{~V}^{-1}$ for $\mathrm{NO}_{3}^{-}$(Ellis et al., 1978) and $3.4 \mathrm{~cm}^{2} \mathrm{~s}^{-1} \mathrm{~V}^{-1}$ for $\mathrm{Na}^{+}$(Bohringer et al., 1987) under typical operation conditions ( $2-4 \mathrm{kV}$ across the IMR). However, when using electrospray as a source and sampling ambient air of different humidity, the reagent ions can be solvated by methanol or water clusters (Horning et al., 1974; Garvey et al., 1994). As the ion mobility of solvated reagent ions is likely smaller than that for un-solvated reagent ions, the 
ion-molecule reaction time between solvated reagent ions and gas-phase analytes in the IMR is expected to be longer than that estimated for the un-solvated ions. There was no evidence of protonated methanol clustering observed when electro-spraying a methanolic solution of the described salts. Although the reagent ion is likely solvated by methanol initially, the sensitivity of the ionization to various trace gases did not appear to be significantly affected in the present study.

The ion source and sample flow rates can significantly affect the performance of the ion source. The ion source flow can aid in the generation and transport of the reagent ions into the IMR, but it may disrupt the initially laminar sample flow, especially when the sample flow is small. However, at large sample flows, the time for the ions to exit the IMR via the sample flow may be comparable to the ion drift time across the IMR at a constant potential. As a result, the sample flow may carry away the reagent ions as well as ion-molecule clusters, lowering the apparent ionization efficiency. Therefore, the ion source flow and sample flow need to be carefully optimized.

For comparison purposes, our prototype source was designed such that it could incorporate a commercial $10 \mathrm{mCi}$ ${ }^{210} \mathrm{Po}$ inline ion source (NRD LLC) as in more typical lowpressure CIMS instruments used for atmospheric composition studies (see introduction). With $\mathrm{CH}_{3} \mathrm{I}$ in UHP $\mathrm{N}_{2}$ as a reagent ion source, this setup was able to produce 0.6$1.8 \times 10^{6}$ counts per second (cps) of reagent ions at atmospheric pressure using an ion source flow rate of 1-2 standard $\mathrm{L} \mathrm{min}^{-1}$ and a sample flow rate of 10 standard $\mathrm{L} \mathrm{min}{ }^{-1}$, with $>2 \mathrm{kV}$ potential across the IMR. Although the commercial ${ }^{210} \mathrm{Po}$ sources are not optimized for ion transmission at low flow rates and high pressures, this intensity is certainly suitable for use in field or laboratory studies.

\subsection{Laboratory characterization}

\subsubsection{Generation of reagent ions and calibration gas standards}

In this study, three negative (i.e., $\mathrm{I}^{-}, \mathrm{NO}_{3}^{-}$, and acetate) and four positive reagent ions (i.e., $\mathrm{Li}^{+}, \mathrm{Na}^{+}, \mathrm{K}^{+}$, and $\mathrm{NH}_{4}^{+}$) were generated by electro-spraying their precursor salt solutions prepared in HPLC-grade MEOH (Fisher Scientific). Sodium iodide ( $\geq 99.5 \%$, EMD), sodium nitrate ( $\geq 99 \%$, Mallinckrodt), potassium acetate (AR(ACS), Macron), ammonium acetate ( $99.2 \%$, Fisher Chemical), and lithium chloride ( $\geq 99 \%$, Mallinckrodt) were used to produce $\mathrm{I}^{-}$and $\mathrm{Na}^{+}, \mathrm{NO}_{3}^{-}, \mathrm{K}^{+}$and acetate, $\mathrm{NH}_{4}^{+}$, and $\mathrm{Li}^{+}$, respectively. All the salts were used as received.

Three calibration gases, i.e., nitric acid $\left(\mathrm{HNO}_{3}\right)$, isotopelabeled formic acid $\left(\mathrm{H}^{13} \mathrm{COOH}\right)$, and isoprene epoxydiols (trans- $\beta$-IEPOX) were used to calibrate the instrument. Gases of nitric acid and formic acid were generated using a custom-built PTFE permeation tube containing respective acid liquids, kept constantly at $40^{\circ} \mathrm{C}$. The permeation rate was determined gravimetrically. IEPOX vapor was generated by passing a flow of UHP $\mathrm{N}_{2}$ over $\sim 200 \mu \mathrm{L}$ IEPOX solution in ethyl acetate kept in a glass bulb at room temperature. The concentration of IEPOX in the flow exiting the bulb was determined by an iodide-adduct HR-ToF-CIMS employing a radioactive ion source, for which the sensitivity to IEPOX was calibrated using the method as described previously (Lee et al., 2014). These three gases are common in the atmosphere and span a range in their properties important for CIMS such as acidity, polarity, and size.

\subsubsection{Optimization of operation conditions, calibration, and background determination}

The influence of sample flow and ion source flow on the ion signals was systematically evaluated using $\mathrm{I}^{-}$as the reagent ion. The room air was directly sampled into the IMR at a flow rate ranging from 2 to 20 standard $\mathrm{L} \mathrm{min}^{-1}$. At each sample flow rate, the ratio of ion source flow / sample flow is varied from 0.02 to 0.2 . The $\mathrm{HNO}_{3}$ and $\mathrm{H}^{13} \mathrm{COOH}$ gases were added to the sample flow during the optimization.

Calibrations with $\mathrm{HNO}_{3}, \mathrm{H}^{13} \mathrm{COOH}$, and IEPOX were performed using $\mathrm{I}^{-}$reagent ions under optimized sample flow and ion source flow conditions. Atmospherically relevant concentrations of the calibration gases were obtained by varying the dilution of the source gas in UHP $\mathrm{N}_{2}$ prior to delivery in the sample flow. The observed ion signals as a function of gas concentration allow the determination of the instrument sensitivity. In addition, the sample flow was humidified to a wide relative humidity range (RH; $0-80 \%$, corresponding to water vapor pressure, $P_{\mathrm{H}_{2} \mathrm{O}}$, of $0-25 \mathrm{mbar}$ ) to explore the influence of water vapor on the instrument sensitivity. The determined sensitivities and the dependence on $P_{\mathrm{H}_{2} \mathrm{O}}$ were compared to the measurements by a radioactive iodide-adduct HR-ToF-CIMS. The background signals of the instrument were determined routinely by directly sampling dry UHP $\mathrm{N}_{2}$.

\subsubsection{Chamber experiments of $\alpha$-pinene ozonolysis}

The capability of the instrument for characterizing atmospherically relevant complex organic systems was evaluated by measuring the oxidation products from $\alpha$-pinene ozonolysis using seven different reagent ions described above. Experiments of $\alpha$-pinene ozonolysis were carried out in a $0.75 \mathrm{~m}^{3}$ PTFE chamber operated in continuous-flow mode at the University of Washington. The chamber was first flushed by 12 standard $\mathrm{L} \mathrm{min}^{-1}$ of zero air generated by a Teledyne zero air generator (model 701) for $>72 \mathrm{~h}$. Ozone, generated by flowing ultra-zero air (Praxair) at $5 \mathrm{sccm}$ past a mercury lamp, was delivered to the chamber during the zero air flushing. $\alpha$-Pinene was then added by flowing $100 \mathrm{sccm}$ of UHP $\mathrm{N}_{2}$ through a glass diffusion tube containing pure $\alpha$-pinene and kept in a methanol cold trap at $-40^{\circ} \mathrm{C}$. The initial con- 

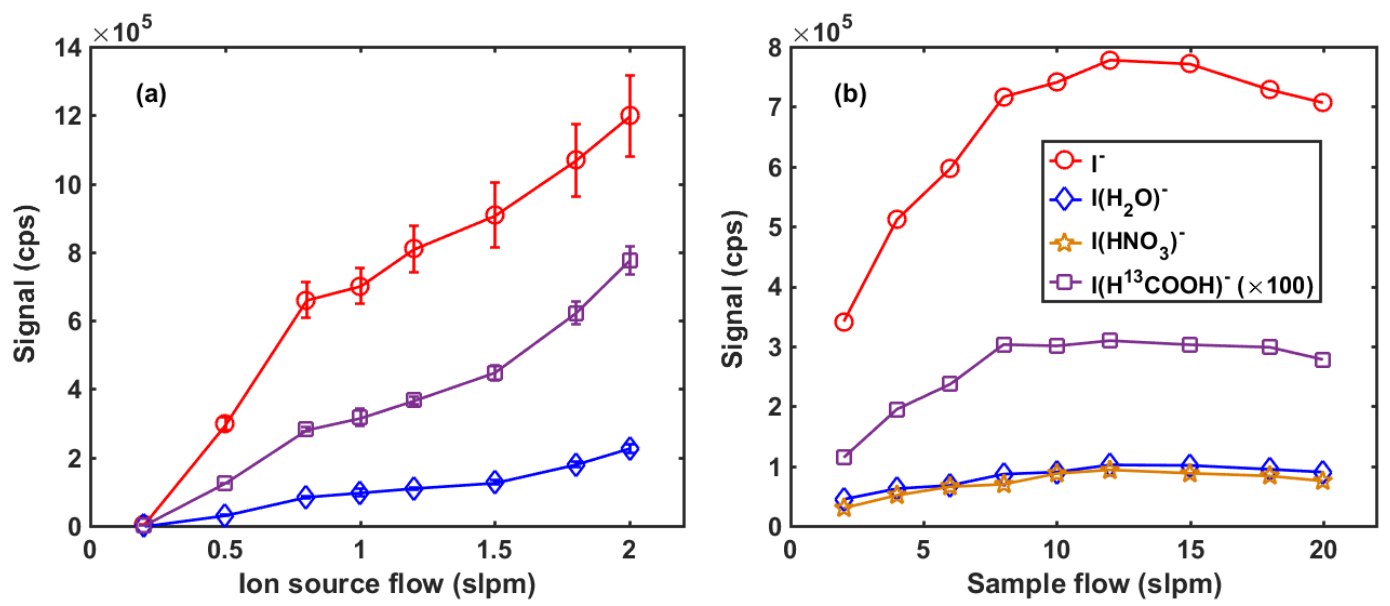

Figure 2. Dependence of ion signals on the ion source flow and sample flow. (a) Ion signals observed as a function of ion source flow during the sampling of humid room air $\left(15 \mathrm{mbar}\right.$ water vapor pressure) containing $\mathrm{H}^{13} \mathrm{COOH}$ at a flow of $10 \mathrm{standard} \mathrm{L}$ min $^{-1}$. (b) Ion signals observed during the sampling of humid room air containing $\mathrm{H}^{13} \mathrm{COOH}$ and $\mathrm{HNO}_{3}$ gas flow rates of 2-20 standard $\mathrm{L} \mathrm{min}^{-1}$ (the ratio of ion source flow / sample flow is fixed at $1: 10)$. The signals for $\mathrm{I}^{\left(\mathrm{H}^{13} \mathrm{COOH}\right)^{-}}$in (a) and (b) are magnified 100 times.

centrations of $\mathrm{O}_{3}$ and $\alpha$-pinene added in the chamber were approximately 75 and $110 \mathrm{ppbv}$, respectively. The oxidation products formed in the chamber were sampled at 10 standard $\mathrm{L} \mathrm{min}^{-1}$ by the HR-ToF-ESCIMS after $48 \mathrm{~h}$ of chamber equilibration.

\section{Results and discussion}

\subsection{Ion source and sample flow optimization}

Figure 2a shows an example using iodide reagent ions of ion signal dependence on the ion source flow rate during sampling of humid air $\left(P_{\mathrm{H}_{2} \mathrm{O}}=15 \mathrm{mbar}\right)$ at 10 standard $\mathrm{L} \mathrm{min}^{-1}$ containing an added $\mathrm{H}^{13} \mathrm{COOH}$ standard. As expected, the reagent ion $\left.\left(\mathrm{I}^{-} \text {and } \mathrm{I}_{(} \mathrm{H}_{2} \mathrm{O}\right)^{-}\right)$signals increase with increasing ion source flow. The increase in the signal for $\mathrm{I}\left(\mathrm{H}^{13} \mathrm{COOH}\right)^{-}$is well correlated with that of the reagent ions. The positive effect of the ion source flow is likely due to more efficient evaporation and transport of reagent ions from the spray evaporation region into the IMR region.

Figure $2 \mathrm{~b}$ shows the ion signals for $\mathrm{I}^{-}, \mathrm{I}\left(\mathrm{H}_{2} \mathrm{O}\right)^{-}$, $\mathrm{I}\left(\mathrm{H}^{13} \mathrm{COOH}\right)^{-}$, and $\mathrm{I}\left(\mathrm{HNO}_{3}\right)^{-}$observed during sampling of humid air $\left(P_{\mathrm{H}_{2} \mathrm{O}}=15 \mathrm{mbar}\right)$ containing $\mathrm{H}^{13} \mathrm{COOH}$ and $\mathrm{HNO}_{3}$ standards at a sample flow rate ranging from 2 to 20 standard $\mathrm{L} \mathrm{min}^{-1}$. The corresponding ion source flow was controlled to always be $1 / 10$ of the sample flow. All ion signals increase initially with the increase in the sample flow, reach maximum values at 12 standard $\mathrm{L} \mathrm{min}^{-1}$, and then decrease slightly with further increase in the sample flow. At low sample flows, the time for the sample flow to pass through the IMR is long compared to electric field-induced ion drift time across the IMR region, so the influence of the sample flow upon ion transit across IMR should be small.
However, the corresponding increase in the ion source flow with the sample flow can promote the generation and transmission of reagent ions into the IMR, thus leading to the increase in ion signals. At large sample flows, the influence of the sample flow on the ion transit across IMR becomes significant and is no longer compensated by the enhancement in ion signals due to the increased ion source flow, hence resulting in a decrease in ion signals. Note that the same measurement was also performed at ion source flow / sample flow ratios ranging from 0.02 to 0.2 . The trend of the ion signal versus the sample flow at each flow ratio is very similar to that shown in Fig. 2b, though the absolute ion signal values are different.

For the characterizations and applications discussed below, the sample flow and ion source flow are kept at 10 and 1 standard $\mathrm{L} \mathrm{min}^{-1}$, respectively, unless otherwise noted, as these are reasonable conditions for use in environmental simulation chambers and in field measurements. We note that the sample flow can be extended to up to 20 standard $\mathrm{L} \mathrm{min}{ }^{-1}$ without significant loss of ion signal, and the optimal ion source flow of 2 standard $\mathrm{L} \mathrm{min}^{-1}$ is essentially the same UHP $\mathrm{N}_{2}$ flow requirement for current ${ }^{210} \mathrm{Po}$-based ion sources (Lee et al., 2014). Further improvements in the spray environment and associated transfer optics will likely further minimize the ion source flow.

\subsection{Evidence of chemical ionization}

Electrospray plumes not only ionize solvated analytes, but also are capable of ionizing gas-phase species (Whitehouse et al., 1986; Chen et al., 1994), the latter termed secondary electrospray ionization (SESI; Wu et al., 2000; Tam and Hill, 2004). SESI-MS has been used for the real-time analysis of a variety of gas-phase analytes, including pharma- 


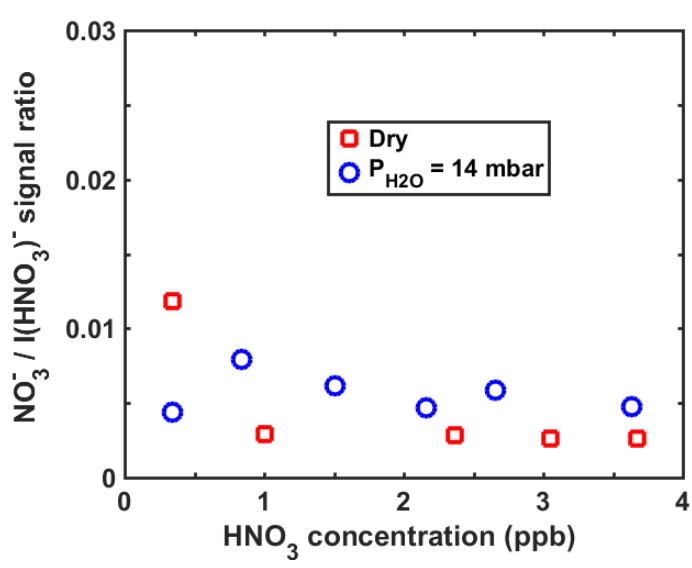

Figure 3. Signal ratio of $\mathrm{NO}_{3}^{-} / \mathrm{I}\left(\mathrm{HNO}_{3}\right)^{-}$as a function of $\mathrm{HNO}_{3}$ concentration under dry and humid conditions observed using iodide as the reagent ion.

ceuticals (Wu et al., 2000; Meier et al., 2012), explosives (Tam and Hill et al., 2004; Aernecke et al., 2015), human metabolites (Martinez-Lozano et al., 2011; Garcia-Gomez et al., 2015), electronic cigarette vapors (Garcia-Gomez et al., 2016), volatile emissions from bacteria cultures (Zhu et al., 2010), food (Bean et al., 2015; Farrell et al., 2017), and plants (Barrios-Collado et al., 2016). In SESI, the electrospray plume and incoming sample flow intersect in the ionization region, and analyte ionization proceeds likely via interactions with both small charged droplets and electrosprayproduced gas-phase reagent ions (Wu et al., 2000). In the present study, by coupling the electrospray source to an orthogonal continuous-flow atmospheric pressure IMR via an evaporation region, we separate the electrospray plume from the incoming samples to avoid SESI, and instead allow for gas-phase chemical ionization.

Under typical operating conditions, the sample flow is likely to transport any un-evaporated droplets away from the effective ionization region in the IMR, thus largely isolating the electrospray plume from the incoming samples, making the ESCI source a chemical ionization source rather than secondary or extractive electrospray ionization (SESI or EESI) source. The evidence of the ESCI source being a chemical ionization source and not SESI or EESI is provided by mon-

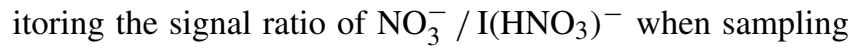
gas-phase $\mathrm{HNO}_{3}$ in the iodide mode. If the direct interaction between electrospray plume and incoming sample flow is important, $\mathrm{HNO}_{3}$ dissolved in charged droplets can dissociate forming $\mathrm{H}^{+}$and $\mathrm{NO}_{3}^{-}$, leading to the generation of $\mathrm{NO}_{3}^{-}$ions in the negative ion mode. Therefore, a high signal ratio of $\mathrm{NO}_{3}^{-} / \mathrm{I}\left(\mathrm{HNO}_{3}\right)^{-}$is expected. Figure 3 shows the signal ratio of $\mathrm{NO}_{3}^{-} / \mathrm{I}\left(\mathrm{HNO}_{3}\right)^{-}$as a function of gas-phase $\mathrm{HNO}_{3}$ concentration under dry and humid conditions observed in

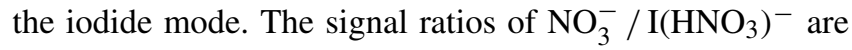
significantly smaller than 0.01 at various $\mathrm{HNO}_{3}$ concentrations, suggesting that the direct interaction of electrospray plume with incoming samples is not important in the ESCI source.

\subsection{Time response of the atmospheric pressure IMR}

The time response of atmospheric pressure orthogonal IMR was determined using nitric acid standard in the iodide mode. $\mathrm{HNO}_{3}$ was delivered from a permeation tube using a $100 \mathrm{sccm}$ continuous UHP $\mathrm{N}_{2}$ flow through a $3 \mathrm{~mm}$ OD Teflon tube to the inlet of the orthogonal IMR. Figure 4 shows the changes in ion signal for $\mathrm{I}\left(\mathrm{HNO}_{3}\right)^{-}$upon placing the $\mathrm{HNO}_{3}$ delivery line at the opening of a $10 \mathrm{~cm}$ length of $2.5 \mathrm{~cm}$ OD Teflon tubing serving as the inlet to the IMR or removing the delivery line from the inlet. Tests were conducted at an ion source flow of 1 standard $\mathrm{L} \mathrm{min}^{-1}$ and sample flow of 5 or 10 standard $\mathrm{L} \mathrm{min}^{-1}$. The increase and decay

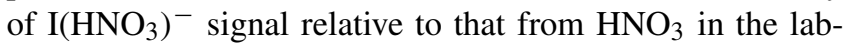
oratory air give an $e$-folding time of about $1 \mathrm{~s}$ for nitric acid under two different flow conditions. This time response value is comparable to or better than that for the low-pressure IMR (one to a few seconds).

\subsection{Sensitivity to selected trace gases}

To assess the performance of the HR-ToF-ESCIMS, we measured the sensitivity to $\mathrm{HNO}_{3}, \mathrm{H}^{13} \mathrm{COOH}$, and IEPOX using $\mathrm{I}^{-}$as the reagent ion. The iodide-based CIMS has been widely used to detect atmospheric inorganic and organic compounds in previous studies (Huey et al., 1995; Kercher et al., 2009; Lee et al., 2014, 2016; Brophy and Farmer, 2015; Lopez-Hilfiker et al., 2016b), though almost exclusively at low pressure (20-80 mbar) as opposed to the atmospheric pressure (1013 mbar) implementation used here. The sensitivity of iodide-based CIMS to a given compound mainly depends on the polarity and hydrogen binding energy of a compound to the $\mathrm{I}^{-}$ion (Lee et al., 2014; Iyer et al., 2016). In the atmospheric pressure ESCIMS, the ion molecule reaction time (a few milliseconds) is set by the electric field, and is up to a factor of 30 or more less than those $(30-120 \mathrm{~ms})$ in low-pressure CIMS instruments (Bertram et al., 2011; Lee et al., 2014, Lopez-Hilfiker et al., 2016a). The shorter reaction time should linearly lower sensitivities. However, the ion-molecule collision frequency is more than a factor of 10 higher in the atmospheric pressure ESCIMS for the same ambient concentrations of analytes. Thus, we would expect the ESCIMS sensitivities to be only slightly lower than those found in the low-pressure CIMS. It is possible that adduct formation is further stabilized by third-body effects and that the ESCIMS could in fact have higher sensitivities for some compounds forming clusters with high excess energy.

Figure 5 shows the signals of $\left(\mathrm{HNO}_{3}\right)^{-}, \mathrm{I}\left(\mathrm{H}^{13} \mathrm{COOH}\right)^{-}$, and $\mathrm{I}(\mathrm{IEPOX})^{-}$per million reagent ion count rate at different atmospherically relevant concentrations of the standards under dry and humid conditions. The signal response is linear within the investigated concentration range for all three trace 

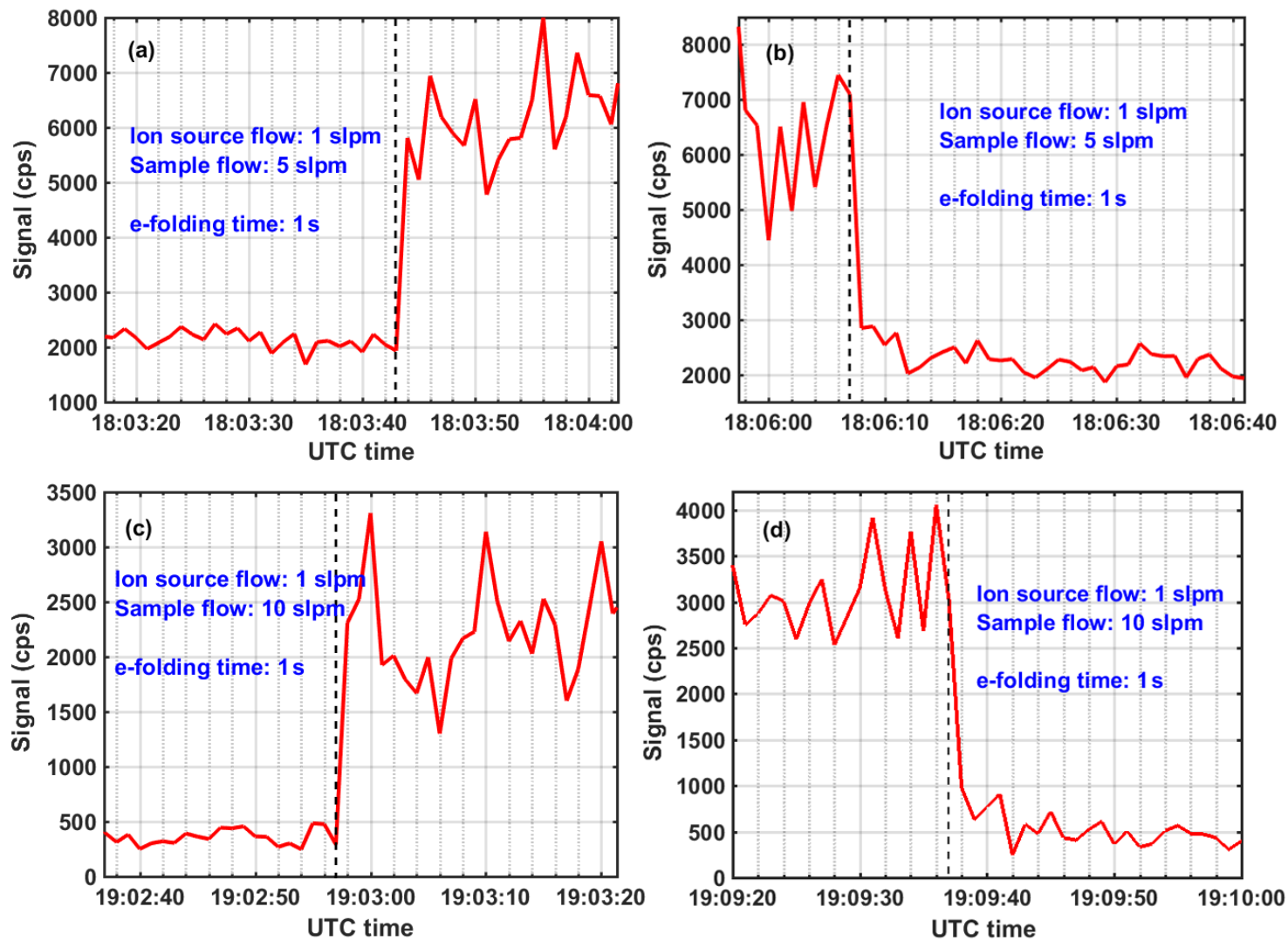

Figure 4. Time series of $\mathrm{I}\left(\mathrm{HNO}_{3}\right)^{-}$observed when sampling (a, b) 5 standard $\mathrm{L} \mathrm{min}^{-1}$ or (c, d) 10 standard L min $^{-1}$ humid room air containing some ambient $\mathrm{HNO}_{3}$ vapor. The ion source flow was 1 standard $\mathrm{Lmin}^{-1}$. The dashed line indicates the time at which the $\mathrm{HNO}_{3}$ standard gas was added or shut off.

gases, with the slope of the linear fit to the ion signals corresponding to the sensitivity per million reagent ion count rate. The HR-ToF-ESCIMS exhibits a sensitivity of 11, 2.4, and $10 \mathrm{cps} \mathrm{pptv}^{-1}$ to $\mathrm{HNO}_{3}, \mathrm{HCOOH}$, and IEPOX, respectively, under dry conditions and $9.1,0.5$, and $1.7 \mathrm{cps} \mathrm{pptv}^{-1}$, respectively, under humid conditions $\left(P_{\mathrm{H}_{2} \mathrm{O}}=14\right.$ or $\left.15 \mathrm{mbar}\right)$. These sensitivities, and those that follow are given in per million cps of reagent ion. Lee et al. (2014) explored the sensitivity of a low-pressure iodide-adduct HR-ToF-CIMS equipped with a radioactive ion source to a number of atmospheric inorganic and organic compounds. They reported sensitivities to $\mathrm{HNO}_{3}, \mathrm{HCOOH}$, and IEPOX of 4.0, 2.9, and $0.39 \mathrm{cps} \mathrm{pptv}^{-1}$, respectively, at $0.2 \mathrm{mbar}$ water vapor pressure in IMR. Using the same instrument as used by Lee et al. (2014), we have more recently obtained higher values of sensitivities to $\mathrm{HCOOH}\left(7 \mathrm{cpsptv}^{-1}\right)$ and IEPOX $\left(10 \mathrm{cps} \mathrm{pptv}^{-1}\right)$ in the laboratory. Thus, the atmosphericpressure ESCIMS and low-pressure CIMS approaches are fairly similar in response to the same compounds. The sensitivity difference in these calibrations is likely attributed to the differences in instrument parameters, including the configurations and pressures of the ion source and IMR, and the ion optic settings within the vacuum chamber that strongly affect ion transmission to the mass spectrometer.

The presence of water vapor can affect sensitivities, either by competing for $\mathrm{I}^{-}$ions, thus lowering the sensitivity, or by accommodating excess energy from the collision to stabilize the iodide-molecule clusters, thereby increasing the sensitivity (Lee et al., 2014; Iyer et al., 2016). Water vapor may also affect sensitivities by changing the size distribution of reagent ion clusters and thus their residence time (ionmolecule reaction time) in the IMR. Moreover, water vapor can affect the transmission of soluble gases through sample tubing. It is difficult to evaluate the effect of changing cluster size distribution as the information regarding the distribution and ion mobility of the reagent ion clusters is currently unavailable. In the current configuration of the ESCIMS, it is also difficult to isolate the sample transfer effect experimentally, as done previously in low-pressure IMR regions by using separate delivery lines for calibrants and water vapor (Lee et al., 2014). Thus, our results shown here reflect a combination of ionization efficiency, cluster distribution, and sample transfer aspects, and the latter could be significant given the $\sim 50 \mathrm{~cm}$ length of tubing used in these tests. 

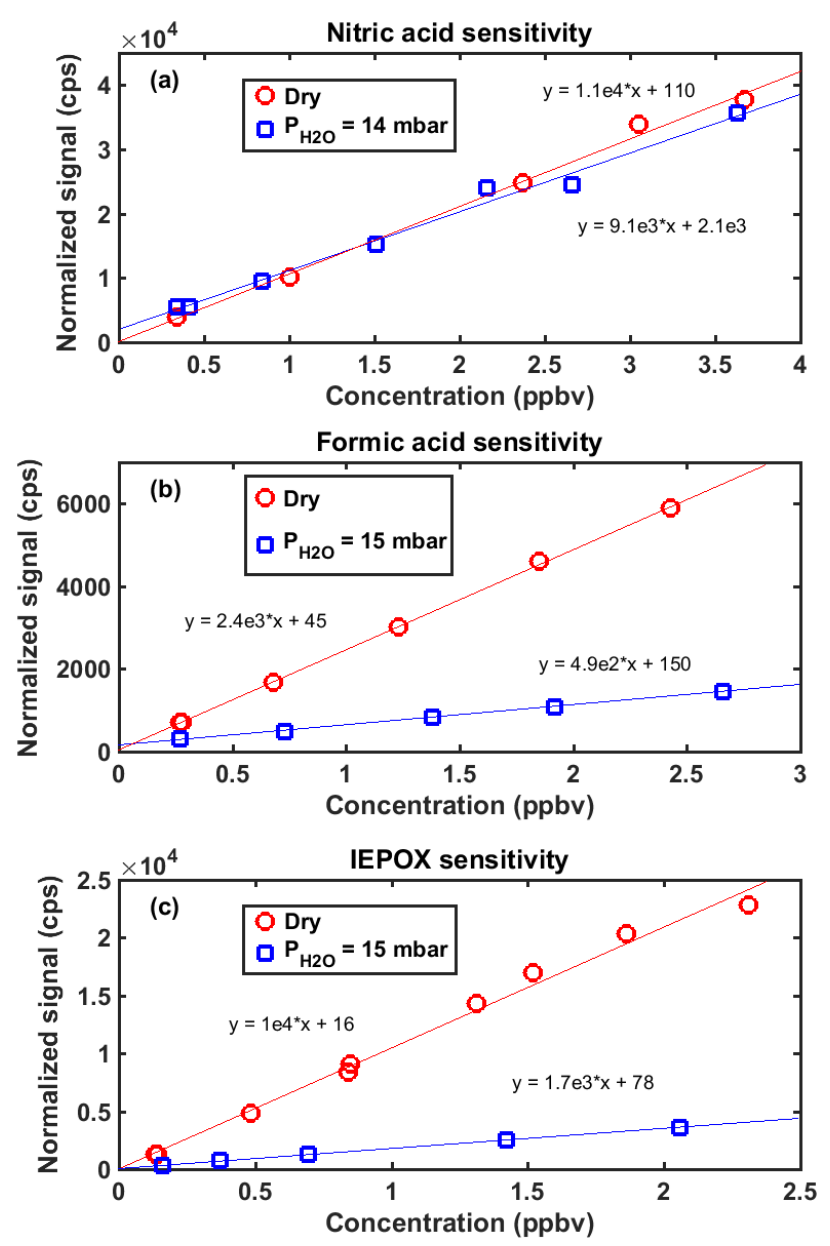

Figure 5. The sensitivity to (a) nitric acid, (b) formic acid, and (c) IEPOX under dry and humid (14 or 15 mbar water vapor pressure) conditions. Signals are normalized by the ratio of observed total reagent ion count rates to a million ion count rate. The normalized signals were observed to be a linear function of the delivered concentration. The slope derived from a linear fit corresponds to the sensitivity per million reagent ion count rates.

Figure 6 shows the dependence of the instrument sensitivities to $\mathrm{HNO}_{3}, \mathrm{H}^{13} \mathrm{COOH}$, and IEPOX on the $P_{\mathrm{H}_{2} \mathrm{O}}$ of the sample flow. The sensitivities to $\mathrm{HNO}_{3}, \mathrm{H}^{13} \mathrm{COOH}$, and IEPOX increase initially with the addition of water vapor at lower $P_{\mathrm{H}_{2} \mathrm{O}}$, reach the maximum values at $4.1,2.2$, and $2.2 \mathrm{mbar}$, respectively, and then decrease with the further increase in $P_{\mathrm{H}_{2} \mathrm{O}}$. Compared to $\mathrm{HNO}_{3}$ and $\mathrm{H}^{13} \mathrm{COOH}$, the positive water vapor effect on the sensitivity at low $P_{\mathrm{H}_{2} \mathrm{O}}$ for IEPOX is significantly smaller. Lee et al. (2014) investigated the effects of water vapor on the sensitivity of a low-pressure iodide-adduct HR-ToF-CIMS in the $P_{\mathrm{H}_{2} \mathrm{O}}$ (water vapor pressure in IMR) range of $0-0.8 \mathrm{mbar}$, and found a positive water vapor dependence for the sensitivity to $\mathrm{HNO}_{3}$ and an approximately inverse U-shaped dependence for the sensitivity to $\mathrm{HCOOH}$. In general, the trends for the sensitivities to $\mathrm{HNO}_{3}$ and $\mathrm{HCOOH}$ versus $P_{\mathrm{H}_{2} \mathrm{O}}$ observed by Lee et al. (2014)

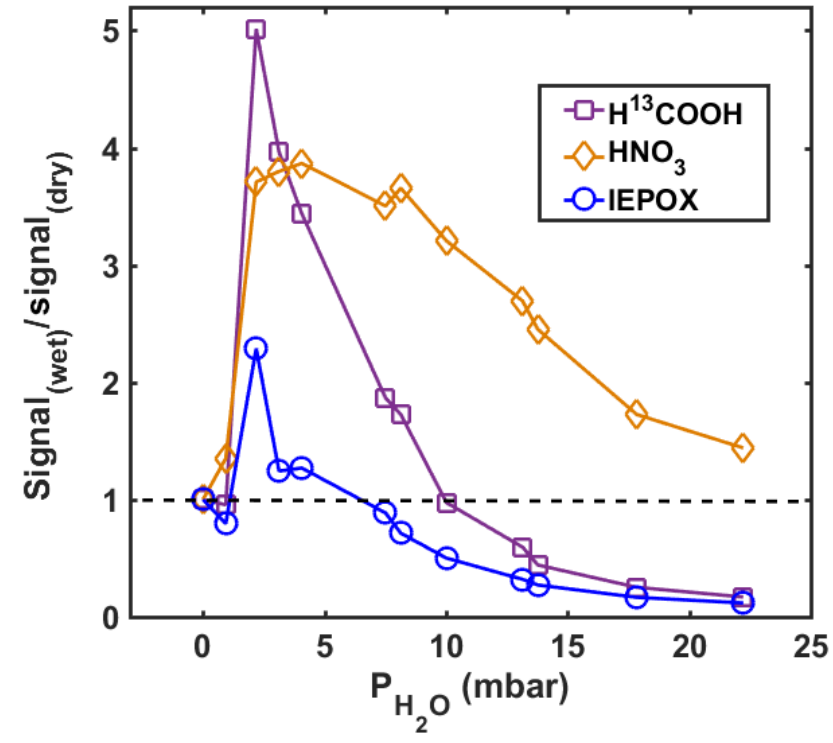

Figure 6. Normalized signal of $\mathrm{I}\left(\mathrm{HNO}_{3}\right)^{-}, \mathrm{I}\left(\mathrm{H}^{13} \mathrm{COOH}\right)^{-}$, and $\mathrm{I}(\mathrm{IEPOX})^{-}$as a function of water vapor pressure $\left(P_{\mathrm{H}_{2} \mathrm{O}}\right)$ in the IMR. The signal of iodide-analyte clusters is first normalized by the total reagent ion $\left.\left(\mathrm{I}^{-} \text {and } \mathrm{I}_{2} \mathrm{O}\right)^{-}\right)$signals. The resulting normalized signal at each $P_{\mathrm{H}_{2} \mathrm{O}}$ was then normalized again to the respective value under dry conditions $\left(P_{\mathrm{H}_{2} \mathrm{O}}=0\right.$, dry UHP $\left.\mathrm{N}_{2}\right)$.

are consistent with those at $P_{\mathrm{H}_{2} \mathrm{O}}<5$ mbar observed in the present study. In addition, recent measurements using the same low-pressure iodide-adduct HR-ToF-CIMS in our lab show that the addition of water vapor with $P_{\mathrm{H}_{2} \mathrm{O}}$ of 0.26 Torr has no significant impacts on the sensitivity to IEPOX, consistent with the relatively weak humidity dependence of the sensitivity to IEPOX at low $P_{\mathrm{H}_{2} \mathrm{O}}$ observed in the present study. The sharp decrease in the sensitivities at higher $P_{\mathrm{H}_{2} \mathrm{O}}$ as seen in Fig. 6 is therefore likely a result of the competitive consumption of $\mathrm{I}^{-}$ions by water vapor, which dominates over the kinetic stabilization effect of water for the ion-molecule clusters, as well as a larger wall partitioning in the sampling tube under these conditions.

\subsection{Instrument backgrounds and detection limits}

The background signals for the instrument arise mainly from the impurities in the electrospray solvent and the salts used for the generation of reagent ions, as well as the desorption of gas species adsorbed onto the wall of the sampling tube and IMR. The instrument backgrounds were routinely measured by sampling UHP $\mathrm{N}_{2}$. Figure 7 shows a typical highresolution mass spectrum in the $\mathrm{I}^{-}$mode recorded when sampling UHP $\mathrm{N}_{2}$. The spectrum recorded during the addition of $\mathrm{HNO}_{3}, \mathrm{H}^{13} \mathrm{COOH}$, and IEPOX to the UHP $\mathrm{N}_{2}$ flow is also displayed for comparison. The typical backgrounds for $\mathrm{HNO}_{3}, \mathrm{H}^{13} \mathrm{COOH}$, and IEPOX were measured to be 800 , 240 , and $50 \mathrm{cps}$, respectively. It is noted that the instrument backgrounds can be reduced by using higher purity electro- 

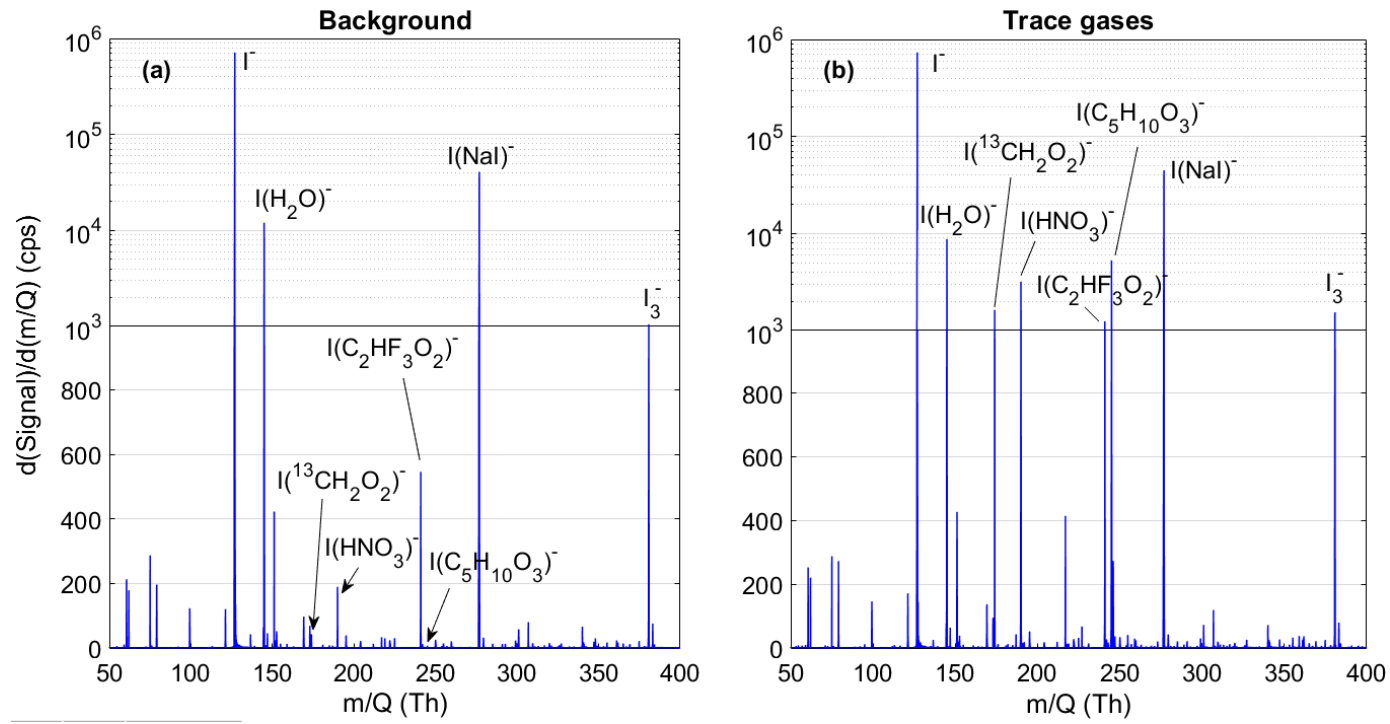

Figure 7. High-resolution mass spectra collected when sampling (a) UHP $\mathrm{N}_{2}$ and (b) UHP $\mathrm{N}_{2}$ containing $\mathrm{HNO}_{3}, \mathrm{H}^{13} \mathrm{COOH}$, and IEPOX gases.

spray solvents and reagent ion precursor salts, or by using a larger sample flow that can dilute the background concentration of the species desorbed from the wall. Moreover, many experiments adding large concentrations of these standards to the sampling tube had been performed over months, and thus it is likely that these backgrounds are anomalously high.

Assuming the uncertainty in the signal and background follows Poisson counting statistics, the signal-to-noise $(S / N)$ ratio can be determined from Eq. (1) (Bertram et al., 2011):

$$
\frac{S}{N}=\frac{C_{f}[X] t}{\sqrt{C_{f}[X] t+2 B t}}
$$

where $C_{f}$ is the instrument sensitivity; $[X]$ is the concentration for a trace gas; $B$ is the background count rate; $t$ is the integration time. We define the detection limit of the HRToF-ESCIMS for a trace gas as the concentration that gives rise to an $S / N$ ratio of 3 . Using the measured instrument sensitivities and backgrounds, we calculate a detection limit of 4.9, 12.5, and 1.4 pptv for $\mathrm{HNO}_{3}, \mathrm{H}^{13} \mathrm{COOH}$, and IEPOX, respectively, for $5 \mathrm{~s}$ averaging, in the $\mathrm{I}^{-}$mode. These limits of detection are comparable to those for a low-pressure iodide-adduct HR-ToF-CIMS in our lab (Lee et al., 2014).

\subsection{Application to chamber studies of $\alpha$-pinene ozonolysis}

\subsubsection{Raw mass spectra}

Gas mixtures formed by ozonolysis of $\alpha$-pinene in a steadystate chamber were used to assess the capabilities of this technique for characterizing complex organic systems of atmospheric relevance. Three negative ions (i.e., $\mathrm{I}^{-}, \mathrm{NO}_{3}^{-}$, ac- etate) and four positive ions (i.e., $\mathrm{Li}^{+}, \mathrm{Na}^{+}, \mathrm{K}^{+}, \mathrm{NH}_{4}^{+}$) were used as reagent ions for measurements. High-resolution peak fitting was performed and reasonable molecular formulae were assigned for detected ions that have intensity higher than $5 \mathrm{cps}$ in all seven ion modes. Many ions are present at $<5 \mathrm{cps}$, which were excluded from the high-resolution fittings to ease the number of identifications required for comparison of several different reagent ion spectra. Although these lower signal ions might be of importance to various mechanisms of particle growth or organic radical chemistry, identifying their compositions was deemed beyond the scope of this paper. Overall, the results show that the ions observed in $\mathrm{NO}_{3}^{-}$and four positive ion modes are in the form of ion-molecule clusters, whereas those observed in $\mathrm{I}^{-}$and acetate modes are either ion-molecule clusters or molecular ions. The iodide clusters can be easily distinguished from iodide-free molecular ions due to the large negative mass defects of iodide (Lee et al., 2014), although this advantage weakens at sufficiently high masses $(>\sim 500 \mathrm{~m} / Q$ for a resolution of 5000). In contrast, broadly distinguishing between acetate-neutral clusters and de-protonated organic ions in the acetate mode remains a challenge when using nonisotopically labeled acetate and operating the instrument in a cluster-transmitting mode with no comprehensive voltage scanning experiments (Lopez-Hilfiker et al., 2015; Brophy and Farmer, 2016), as is the case in the present study. As a result, the high-resolution ions observed in the acetate mode cannot be confidently assigned to $\alpha$-pinene ozonolysis products and are excluded from further discussions.

Examples of high-resolution mass spectra of $\alpha$-pinene ozonolysis products derived in $\mathrm{I}^{-}$and $\mathrm{NO}_{3}^{-}$modes are given in Fig. 8 and the spectra obtained in four positive ion modes are given in Fig. 9. The iodide-mode mass spectrum of 

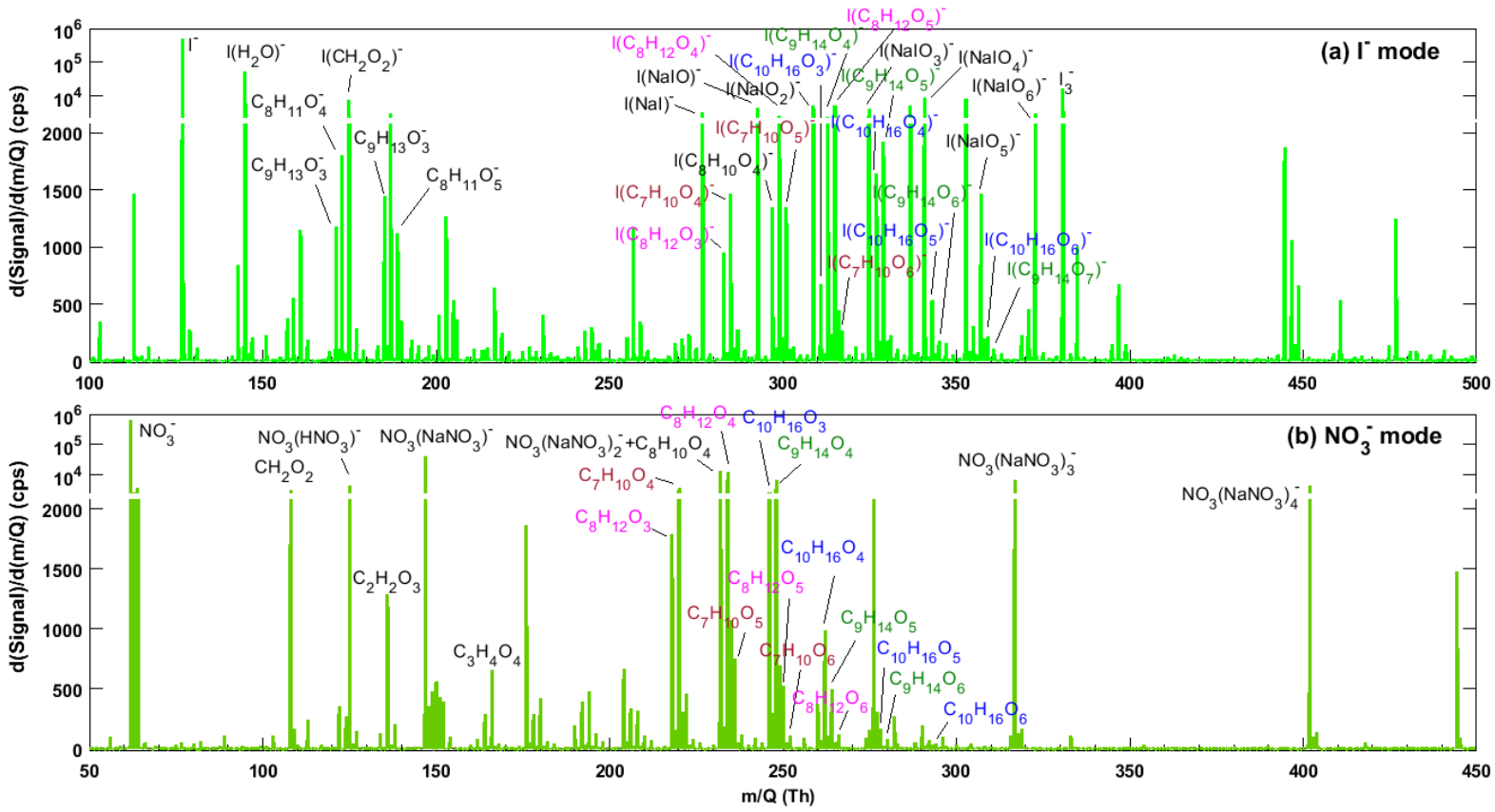

Figure 8. High-resolution mass spectra obtained during ozonolysis of $\alpha$-pinene in a steady-state chamber in (a) $\mathrm{I}^{-}$and (b) $\mathrm{NO}_{3}^{-}$modes. For $\mathrm{NO}_{3}^{-}$mode, the chemical formulae of organic ion clusters are shown without the corresponding $\mathrm{NO}_{3}^{-}$adduct for clarity as, unlike $\mathrm{I}^{-}$mode, organic ions without a $\mathrm{NO}_{3}^{-}$adduct were negligible components of the spectrum.
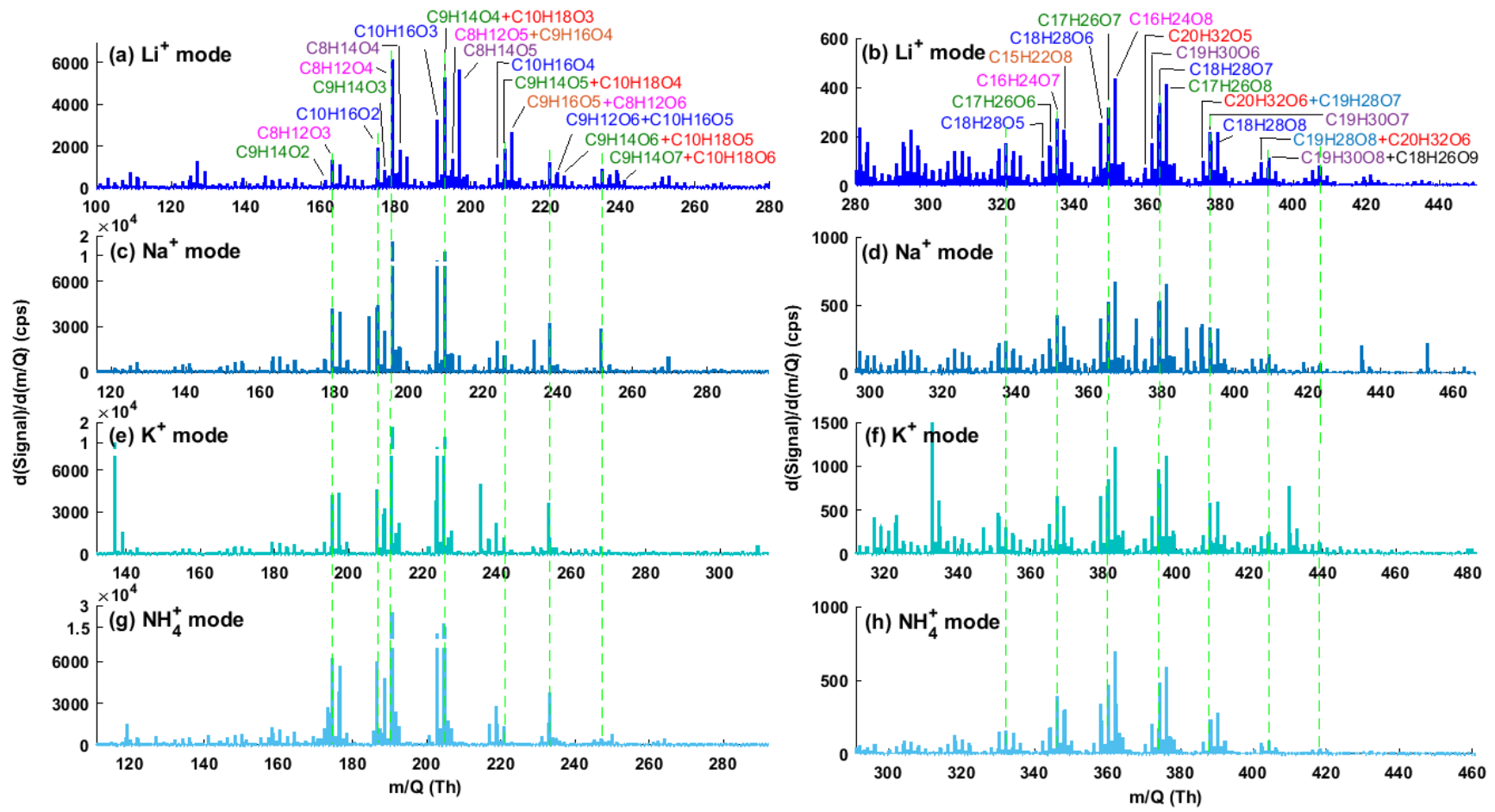

Figure 9. High-resolution mass spectra of $\alpha$-pinene ozonolysis products in (a, c, e, g) monomer and $(\mathbf{b}, \mathbf{d}, \mathbf{f}, \mathbf{h})$ dimer regions observed in $(\mathbf{a}, \mathbf{b}) \mathrm{Li}^{+}$mode, $(\mathbf{c}, \mathbf{d}) \mathrm{Na}^{+}$mode, $(\mathbf{e}, \mathbf{f}) \mathrm{K}^{+}$mode, and $(\mathbf{g}, \mathbf{h}) \mathrm{NH}_{4}^{+}$mode. The chemical formulae of the detected organics are given for major peaks observed in the mass spectra. To allow direct comparison, the reagent ion adduct has been removed from the detected cluster in each spectrum. 

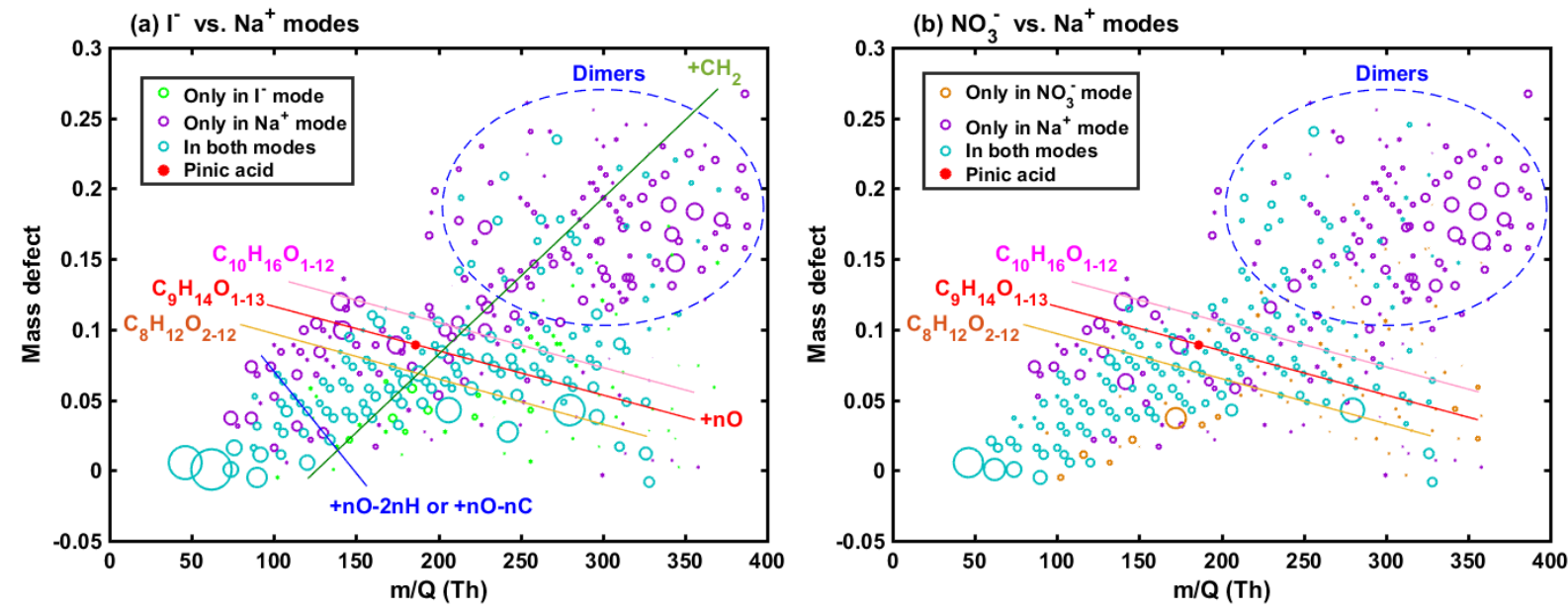

Figure 10. Comparisons of mass defect plots derived in (a) $\mathrm{I}^{-}$and $\mathrm{Na}^{+}$modes and (b) $\mathrm{NO}_{3}^{-}$and $\mathrm{Na}^{+}$modes during ozonolysis of $\alpha$-pinene in a steady-state chamber. To compare the mass defect plot obtained in two different ion modes, the reagent ions in observed clusters are excluded for the mass defect calculation, and the signals are normalized to the corresponding pinic acid intensity in each mode (see text for details). The purple circles do not necessarily mean such ions were undetected in the negative mode as they may have very small signal $(<5 \mathrm{cps})$ and be excluded from the high-resolution fitting.

the ozonolysis products obtained here is overall similar to that obtained using the low-pressure iodide-adduct HR-ToFCIMS (see Fig. S1 in the Supplement). It can be seen that peaks assigned to monomeric products $\left(\leq \mathrm{C}_{10}\right)$ are apparent in all ion modes, while peaks associated with dimeric species are evident only in the positive ion mode (discussed further below). Peak distributions in both monomer and dimer regions is very similar for $\mathrm{Li}^{+}, \mathrm{Na}^{+}, \mathrm{K}^{+}$, and $\mathrm{NH}_{4}^{+}$, suggesting these positive ions likely have a similar selectivity to $\alpha$ pinene ozonolysis products. It is interesting to note that in negative ion modes, ion clusters of precursor salt molecules (e.g., $\mathrm{I}(\mathrm{NaI})^{-}$and $\left.\mathrm{NO}_{3}\left(\mathrm{NaNO}_{3}\right)_{n}^{-}\right)$were observed with high intensities. These ions can be used as excellent mass calibration species.

\subsubsection{Mass defect plots}

To better compare the sensitivity and selectivity between this subset of negative and positive reagent ions, the mass defects of identified products are plotted against their exact mass for $\mathrm{I}^{-}, \mathrm{NO}_{3}^{-}$, and $\mathrm{Na}^{+}$modes. Figure 10 shows the comparisons of mass defect plots between $\mathrm{I}^{-}$(or $\mathrm{NO}_{3}^{-}$) mode and $\mathrm{Na}^{+}$ mode. In the mass defect plots, the green, yellow, and purple open circles represent the products observed only in one ion mode and their size is proportional to the signal intensity of observed clusters. The blue open markers in the plots represent the products identified in both ion modes of comparison and their size is proportional to the square root of the pinic acid-normalized signal intensity ratio $(R)$ between the two ion modes:

$R=\frac{S_{A^{-}, i} / S_{A^{-}, \mathrm{PA}}}{S_{\mathrm{Na}^{+}, i} / S_{\mathrm{Na}^{+}, \mathrm{PA}}}$, where, $S_{A^{-}, i}$ and $S_{A^{-}, \text {PA }}$ are the signal intensity of clusters for product $i$ and pinic acid in $\mathrm{I}^{-}$(or $\mathrm{NO}_{3}^{-}$) mode, respectively; $S_{\mathrm{Na}^{+}, i}$ and $S_{\mathrm{Na}^{+}, \mathrm{PA}}$ are the signal intensity of product $i$ and pinic acid in $\mathrm{Na}^{+}$mode, respectively. As pinic acid $\left(\mathrm{C}_{9} \mathrm{H}_{14} \mathrm{O}_{4}\right)$ is among the most abundant products observed in $\mathrm{I}^{-}, \mathrm{NO}_{3}^{-}$, and $\mathrm{Na}^{+}$modes (see Figs. 8 and 9), the value of $R$ (i.e., the size of the markers relative to that for pinic acid; red solid circles) can be an indicator of the relative sensitivity of $\mathrm{I}^{-}$(or $\mathrm{NO}_{3}^{-}$) and $\mathrm{Na}^{+}$to the oxidation products.

In the monomer region of the mass defect plots, the less oxidized products observed in both modes of comparison generally have a value of $R \leq 1$ (the blue markers have sizes smaller than or close to that of pinic acid). Thus, $\mathrm{Na}^{+}$is generally more sensitive to less oxidized species than $\mathrm{I}^{-}$and $\mathrm{NO}_{3}^{-}$, and most of products observed only in the $\mathrm{Na}^{+}$mode show very low oxygen contents $\left(n_{\mathrm{O}} \leq 3\right)$. As many of these species have signal intensities larger than $1000 \mathrm{cps}$, their absence in $\mathrm{I}^{-}$and $\mathrm{NO}_{3}^{-}$modes suggests that $\mathrm{I}^{-}$and $\mathrm{NO}_{3}^{-}$ are extremely insensitive to these least oxidized species, in agreement with the observations in previous studies (Lee et al., 2014; Hyttinen et al., 2015; Iyer et al., 2016). In contrast, the more oxidized products observed in both modes of comparison show a wide range of $R$ values (e.g., $R \leq 1$ or $R \geq 1$, corresponding to the blue markers having sizes smaller or larger than that of pinic acid). This indicates that $\mathrm{I}^{-}, \mathrm{NO}_{3}^{-}$, and $\mathrm{Na}^{+}$are all sensitive to more oxidized species but have different sensitivities to a specific species. In fact, some highly oxidized products having high oxygen contents $\left(n_{\mathrm{O}} \geq 5\right)$ are observed only in one of these three ion modes. Note that most of these products have signal intensities lower than $50 \mathrm{cps}$, suggesting that they likely have very low con- 
centrations, which are below the detection limit in the other two modes.

The selectivity of $\mathrm{I}^{-}$and $\mathrm{NO}_{3}^{-}$toward more oxidized species as suggested here is consistent with the observations in previous studies (Lee et al., 2014; Berndt et al., 2016), which showed that these two reagent ions can have distinct sensitivities to the oxidized species having similar oxygen contents, depending on the identities and locations of the functional groups. It is clear in Fig. 10 that some very small species (e.g., $\mathrm{CH}_{2} \mathrm{O}_{2}, \mathrm{CH}_{2} \mathrm{O}_{3}, \mathrm{C}_{2} \mathrm{H}_{2} \mathrm{O}_{3}$, and $\mathrm{C}_{2} \mathrm{H}_{4} \mathrm{O}_{3}$ ) have a value of $R$ significantly larger than 1 , indicating that $\mathrm{I}^{-}$and $\mathrm{NO}_{3}^{-}$are markedly more sensitive to these small species than is $\mathrm{Na}^{+}$.

Comparisons of the mass defect plots in the dimers region show a large difference in the detection of the gas-phase dimers between $\mathrm{I}^{-}$(or $\mathrm{NO}_{3}^{-}$) and $\mathrm{Na}^{+}$modes. These dimers have compositions ranging, for example, from $\mathrm{C}_{15} \mathrm{H}_{26} \mathrm{O}_{3}$ to $\mathrm{C}_{20} \mathrm{H}_{32} \mathrm{O}_{7}$. We note that many of these dimers have been recently detected in the gas phase using a low-pressure iodideadduct HR-ToF-CIMS in a boreal forest environment (Mohr et al., 2017). Thus, while the lower detection efficiency of dimers in this work using $\mathrm{I}^{-}$or $\mathrm{NO}_{3}^{-}$may be from differences in reagent ion sensitivities, we suspect that differences in ion optic settings between negative and positive ion modes that affect ion transmission efficiencies at large massto-charge ratios is a more likely explanation. These settings were not optimized in this work, and improvements to high mass transmission in negative ion mode are ongoing. Therefore, we refrain from concluding about the relative detection efficiency of dimers in negative ion mode using the atmospheric pressure ESCI.

Figure 11 shows box plots for the $\mathrm{O}: \mathrm{C}$ ratio of monomeric products from $\alpha$-pinene ozonolysis detected in $\mathrm{I}^{-}, \mathrm{NO}_{3}^{-}$, and $\mathrm{Na}^{+}$modes. The $\mathrm{O}: \mathrm{C}$ values for all the percentiles observed in $\mathrm{I}^{-}$and $\mathrm{NO}_{3}^{-}$modes are overall similar, whereas the corresponding values observed in $\mathrm{Na}^{+}$mode are obviously smaller. In addition, more than half of products observed in the three modes have a $\mathrm{O}: \mathrm{C}$ ratio larger than 0.8 . These results are consistent with the observations from Fig. 10, where $\mathrm{I}^{-}, \mathrm{NO}_{3}^{-}$, and $\mathrm{Na}^{+}$are all sensitive to highly oxygenated organics, but the former two reagent ions are insensitive to less oxygenated organics as compared to $\mathrm{Na}^{+}$.

In summary, these comparisons suggest that there is not a reagent ion that captures all components of $\alpha$-pinene ozonolysis with equally high sensitivity. Therefore, to gain a comprehensive view of a complex organic system, a combination of reagent ions with different selectivity is needed.

\subsubsection{Declustering scans}

Ion-molecule clusters, depending on their binding energies, may break apart due to collision-induced dissociation (i.e., declustering) during transmission through the ion optics within the vacuum chamber. In general, clusters with stronger binding energies can more easily survive decluster-

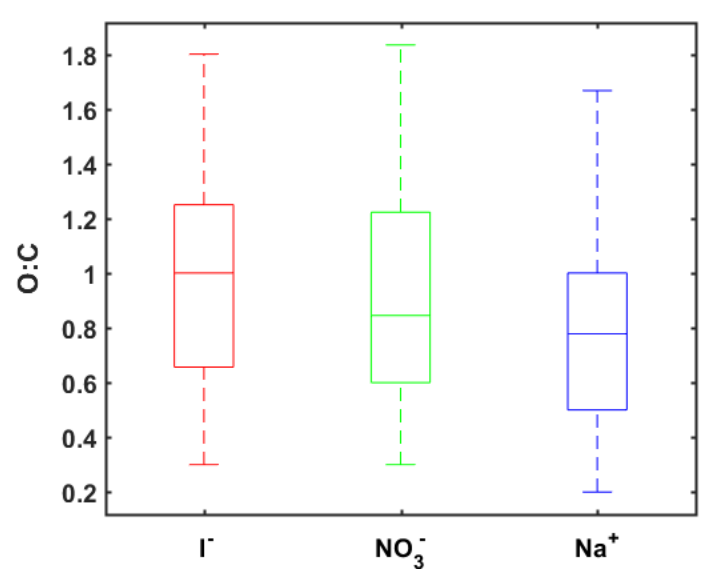

Figure 11. Box plots showing the 5th, 25th, 50th, 75th, and 95th percentiles for the $\mathrm{O}: \mathrm{C}$ ratio of monomeric products from $\alpha$-pinene ozonolysis detected in different ion modes.

ing in the vacuum chamber, and thus the instrument likely has higher sensitivities to the corresponding analytes, and the observed sensitivities should be closer to those calculated by ion-molecule collision rates. Declustering scanning, which is performed by systematically increasing the voltage difference $(\Delta V)$ between first and the second quadrupole sections of the MS, provides insights into the binding energies of clusters (Lopez-Hilfiker et al., 2016a). Figure 12 shows the declustering scans of clusters containing $\mathrm{C}_{10} \mathrm{H}_{16} \mathrm{O}_{2-8}$ and $\mathrm{C}_{9} \mathrm{H}_{14} \mathrm{O}_{3-8}$ products in $\mathrm{I}^{-}$and $\mathrm{NO}_{3}^{-}$modes. It is clear that, with the increase in electrical field strength, the cluster signals for products having higher oxygen contents generally decay more slowly than those having lower oxygen contents. This is consistent with the fact that $\mathrm{I}^{-}$and $\mathrm{NO}_{3}^{-}$ions generally bind more strongly to compounds containing more hydroxy or hydroperoxy moieties (Lee et al., 2014; Hyttinen et al., 2015; Iyer et al., 2016). We note that the trends of decay for $\mathrm{C}_{10} \mathrm{H}_{16} \mathrm{O}_{2-8}$ iodide clusters are in excellent agreement with previous measurements using a low-pressure iodideadduct HR-ToF-CIMS (Lopez-Hilfiker et al., 2016a).

Declustering scans in $\mathrm{Li}^{+}, \mathrm{Na}^{+}, \mathrm{K}^{+}$, and $\mathrm{NH}_{4}^{+}$modes show that the cluster signals for the most abundant monomeric products such as $\mathrm{C}_{10} \mathrm{H}_{16} \mathrm{O}_{2-5}$ and $\mathrm{C}_{9} \mathrm{H}_{14} \mathrm{O}_{2-5}$ increase initially with increasing $\Delta V$ and then decrease with further increase in $\Delta V$. The reason for the initial increase in cluster signals is unclear, but might involve secondary ion chemistry and/or slight changes in ion transmission efficiency of the instrument. Here, we use the declustering scans of dimers instead of $\mathrm{C}_{9}$ and $\mathrm{C}_{10}$ monomers to compare the binding energies of four positive reagent ions.

As can be seen in Fig. 13, the decay rate of the cluster signals in four positive ion modes follows the order $\mathrm{NH}_{4}^{+}>\mathrm{K}^{+}>\mathrm{Na}^{+}>\mathrm{Li}^{+}$. This indicates an order of $\mathrm{Li}^{+}>\mathrm{Na}^{+}>\mathrm{K}^{+}>\mathrm{NH}_{4}^{+}$for the binding energies of the clusters, consistent with expectations from charge density considerations. In each ion mode, the cluster signals for 

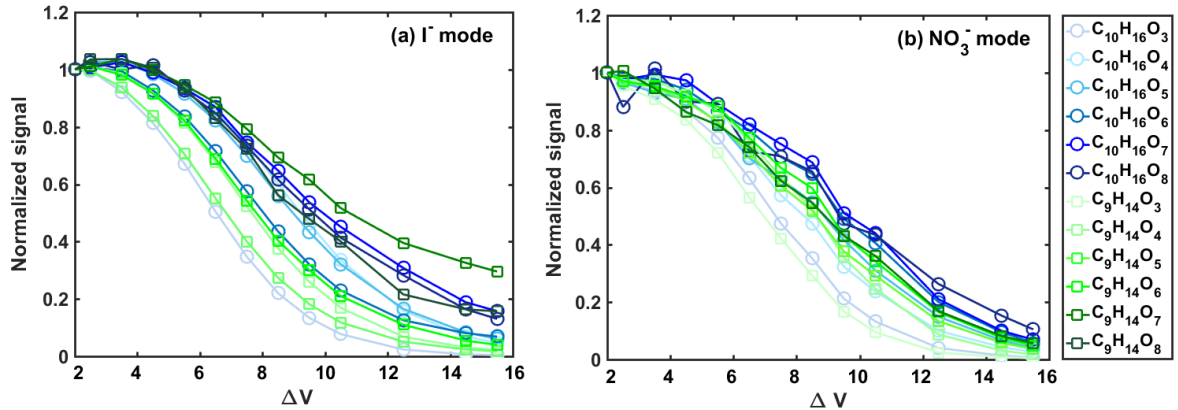

Figure 12. Declustering scans of products $\mathrm{C}_{10} \mathrm{H}_{16} \mathrm{O}_{2-8}$ and $\mathrm{C}_{9} \mathrm{H}_{14} \mathrm{O}_{3-8}$ formed by the ozonolysis of $\alpha$-pinene in (a) $\mathrm{I}^{-}$and (b) $\mathrm{NO}_{3}^{-}$ modes. $\Delta V$ denotes the voltage differences between the end of first and the entrance to the second quadrupole sections of the mass spectrometer. Signals at each $\Delta V$ are normalized to that obtained at the weakest declustering strength (i.e., $\Delta V=2 \mathrm{~V}$ ).
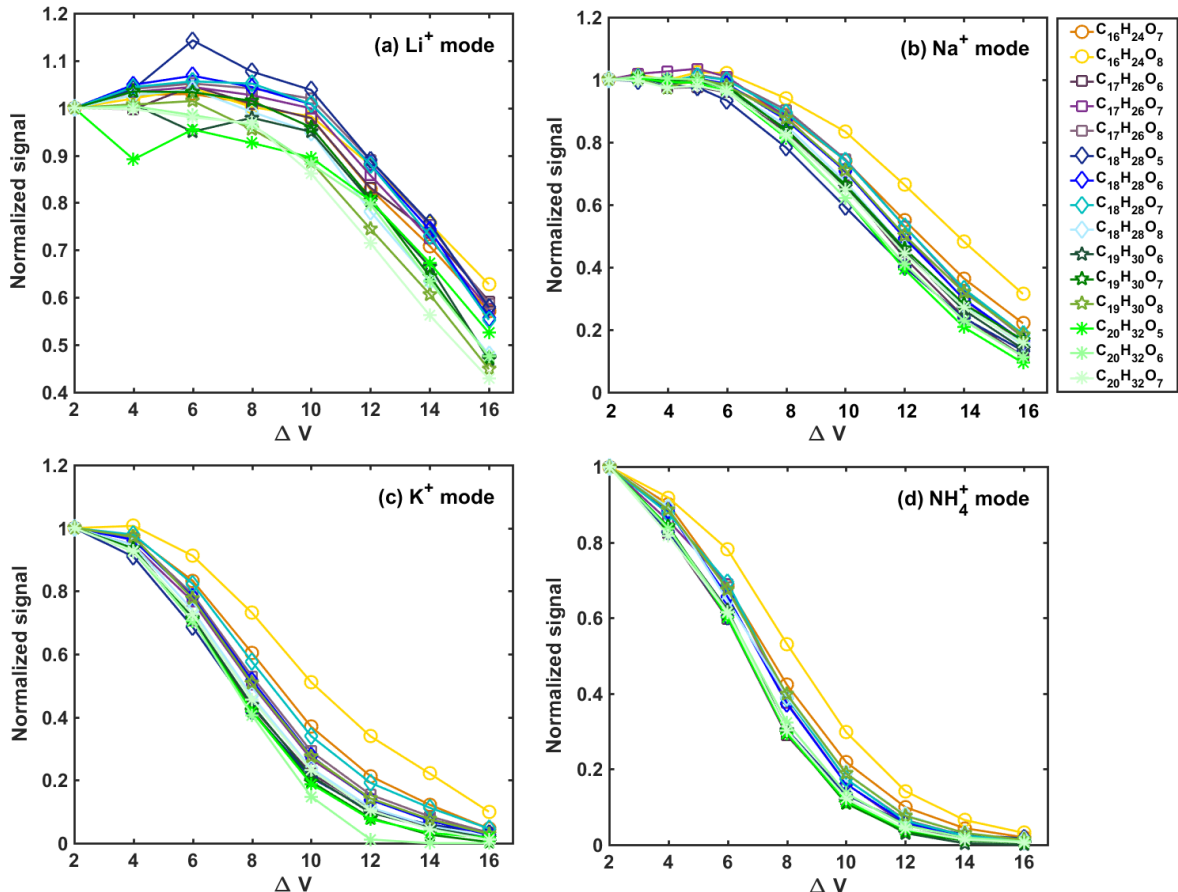

Figure 13. Declustering scans of the 15 most abundant dimers formed by the ozonolysis of $\alpha$-pinene in (a) $\mathrm{Li}^{+}$mode, (b) $\mathrm{Na}^{+}$mode, (c) $\mathrm{K}^{+}$ mode, and (d) $\mathrm{NH}_{4}^{+}$mode. $\Delta V$ denotes the voltage differences between the first and second quadrupole sections of the mass spectrometer. Signals at each $\Delta V$ are normalized to that obtained at the weakest declustering strength (i.e., $\Delta V=2 \mathrm{~V}$ ).

smaller dimers generally decay more slowly than those for larger dimers, suggesting these positive ions can more strongly bind to the smaller dimers, likely due to the higher polarity or the smaller steric effect for smaller dimers. It is worth noting that in the $\mathrm{Li}^{+}$mode, these dimer ions have $\Delta V_{50}$ values of $\sim 15 \mathrm{~V}$, suggesting they are very strongly bound, with a binding enthalpy of $\sim 70 \mathrm{kcal} \mathrm{mol}^{-1}$ according to the relationship between $\Delta V_{50}$ and cluster binding energies determined by Lopez-Hilfiker et al. (2016a).

\section{Conclusion}

We report an electrospray chemical ionization (ESCI) source coupled to a HR-ToF-MS for the real-time online measurement of atmospheric organic and inorganic species in the gas phase. The ESCI source is unique in that it does not rely on radioactive materials or X-ray radiation that are subject to safety regulations, and allows for the production of reagent ions (e.g., alkaline cations) that are not available in current CIMS techniques. Calibration experiments using nitric acid, formic acid, and IEPOX gas standards show that the HRToF-ESCIMS using iodide reagent ions has sensitivities and limits of detection comparable to those obtained for a low- 
pressure iodide-adduct HR-ToF-CIMS using a radioactive ion source. The detection of oxidized organic compounds formed from $\alpha$-pinene ozonolysis in a chamber using seven different reagent ions (e.g., $\mathrm{I}^{-}, \mathrm{NO}_{3}^{-}$, acetate, $\mathrm{Li}^{+}, \mathrm{Na}^{+}, \mathrm{K}^{+}$, and $\mathrm{NH}_{4}^{+}$) shows different selectivities for these reagent ions and expected ion-adduct binding energy trends. The data demonstrate the capability of this technique for comprehensively characterizing complex organic systems using a combination of reagent ions.

The ESCI source presented here is in its early stages of development. Continued characterization of the sensitivity and selectivity of different reagent ions, especially their dependence on humidity, is needed. Further optimizations of the ion source are also required to improve its performance, especially long-term stability, which is particularly important for field applications. Versions of our prototype source allowed 10 to $24 \mathrm{~h}$ of continuous operation before ion signal degraded, which is certainly suitable for many laboratory experiment durations. A short immersion of the spray tip into HPLC-grade MEOH was enough to return to the same ion signal for another 10 to $24 \mathrm{~h}$, suggesting the reason was simply salt build-up on the spray needle tip altering the spray characteristics. Thus, it is likely that more dilute spray solutions, shorter spray needle tips, a conventional coaxial sheath gas flow around the needle tip, and off-axis spray geometry would greatly improve source stability. Moreover, shifting the spray source further upstream of the entrance capillary would increase ion-molecule reaction times and thus sensitivity, as in Zhao et al. (2010). Finally, applying a dry UHP $\mathrm{N}_{2}$ counter flow at the mass spectrometer entrance capillary would prevent ambient particles and possible charged spray droplets that are not completely evaporated from entering and blocking the capillary tube. This counter flow could also prevent free water molecules from entering the vacuum chamber and promote the dissociation of reagent ion-water clusters, which may lead to an increase in the instrument sensitivity, especially in positive ion mode.

Data availability. Data presented in this study are available from the authors upon request.

\section{The Supplement related to this article is available online at https://doi.org/10.5194/amt-10-3609-2017-supplement.}

Competing interests. The authors declare that they have no conflict of interest.

Acknowledgements. This work was supported by the National Science Foundation (CHE-1404573). Jeremy Chan acknowledges the support of the University of Washington Royalty Research
Fund (grant 65-7716). Felipe D. Lopez-Hilfiker and Jay G. Slowik acknowledge the support from the Swiss National Science Foundation (grant BSSGI0_155846). We are grateful to Dennis Canuelle, the instrument maker, for help in designing and building the ESCI source.

Edited by: Gavin Phillips

Reviewed by: two anonymous referees

\section{References}

Aernecke, M. J., Mendum, T., Geurtsen, G., Ostrinskaya, A., and Kunz, R. R.: Vapor Pressure of Hexamethylene Triperoxide Diamine (HMTD) Estimated Using Secondary Electrospray Ionization Mass Spectrometry, J. Phys. Chem. A, 119, 11514-11522, 2015.

Aljawhary, D., Lee, A. K. Y., and Abbatt, J. P. D.: High-resolution chemical ionization mass spectrometry (ToF-CIMS): application to study SOA composition and processing, Atmos. Meas. Tech., 6, 3211-3224, https://doi.org/10.5194/amt-6-3211-2013, 2013.

Barrios-Collado, C., Garcia-Gomez, D., Zenobi, R., Vidal-deMiguel, G., Ibanez, A. J., and Sinues, P. M. L.: Capturing in Vivo Plant Metabolism by Real-Time Analysis of Low to High Molecular Weight Volatiles, Anal. Chem., 88, 2406-2412, https://doi.org/10.1021/acs.analchem.5b04452, 2016.

Bean, H. D., Mellors, T. R., Zhu, J. J., and Hill, J. E.: Profiling Aged Artisanal Cheddar Cheese Using Secondary Electrospray Ionization Mass Spectrometry, J. Agric. Food Chem., 63, 43864392, https://doi.org/10.1021/jf5063759, 2015.

Berndt, T., Richters, S., Jokinen, T., Hyttinen, N., Kurten, T., Otkjaer, R. V., Kjaergaard, H. G., Stratmann, F., Herrmann, H., Sipila, M., Kulmala, M., and Ehn, M.: Hydroxyl radical-induced formation of highly oxidized organic compounds, Nat. Commun., 7, 13677, https://doi.org/10.1038/ncomms13677, 2016.

Bertram, T. H., Kimmel, J. R., Crisp, T. A., Ryder, O. S., Yatavelli, R. L. N., Thornton, J. A., Cubison, M. J., Gonin, M., and Worsnop, D. R.: A field-deployable, chemical ionization timeof-flight mass spectrometer, Atmos. Meas. Tech., 4, 1471-1479, https://doi.org/10.5194/amt-4-1471-2011, 2011.

Bohringer, H., Fahey, D. W., Lindinger, W., Howorka, F., Fehsenfeld, F. C., and Albritton, D. L.: Mobilities of several massidentified positive and negative ions in air, Int. J. Mass Spectrom., 81, 45-65, 1987.

Breitenlechner, M., Fischer, L., Hainer, M., Heinritzi, M., Curtius, J., and Hansel, A.: PTR3: An Instrument for Studying the Lifecycle of Reactive Organic Carbon in the Atmosphere, Anal. Chem., 89, 5825-5832, https://doi.org/10.1021/acs.analchem.6b05110, 2017.

Brophy, P. and Farmer, D. K.: A switchable reagent ion high resolution time-of-flight chemical ionization mass spectrometer for real-time measurement of gas phase oxidized species: characterization from the 2013 southern oxidant and aerosol study, Atmos. Meas. Tech., 8, 2945-2959, https://doi.org/10.5194/amt-8-29452015, 2015.

Brophy, P. and Farmer, D. K.: Clustering, methodology, and mechanistic insights into acetate chemical ionization using highresolution time-of-flight mass spectrometry, Atmos. Meas. Tech., 9, 3969-3986, https://doi.org/10.5194/amt-9-3969-2016, 2016. 
Chen, Y. H., Hill, H. H., and Wittmer, D. P.: Analytical Merit of Electrospray Ion Mobility Spectrometry as a Chromatographic Detector, J. Microcolumn Sep., 6, 515-524, https://doi.org/10.1002/mcs.1220060511, 1994.

Crounse, J. D., McKinney, K. A., Kwan, A. J., and Wennberg, P. O.: Measurement of gas-phase hydroperoxides by chemical ionization mass spectrometry, Anal. Chem., 78, 6726-6732, 2006.

Ehn, M., Thornton, J. A., Kleist, E., Sipila, M., Junninen, H., Pullinen, I., Springer, M., Rubach, F., Tillmann, R., Lee, B., Lopez-Hilfiker, F., Andres, S., Acir, I. H., Rissanen, M., Jokinen, T., Schobesberger, S., Kangasluoma, J., Kontkanen, J., Nieminen, T., Kurten, T., Nielsen, L. B., Jorgensen, S., Kjaergaard, H. G., Canagaratna, M., Dal Maso, M., Berndt, T., Petaja, T., Wahner, A., Kerminen, V. M., Kulmala, M., Worsnop, D. R., Wildt, J., and Mentel, T. F.: A large source of lowvolatility secondary organic aerosol, Nature, 506, 476-479, https://doi.org/10.1038/nature13032, 2014.

Ellis, H. W., McDaniel, E. W., Albritton, D. L., Viehland, L. A., Lin, S. L., and Mason, E. A.: Transport properties of gaseous ions over a wide energy range - Part II, Atom. Data Nucl. Data, 22, 179-217, 1978.

Farrell, R. R., Fahrentrapp, J., Garcia-Gomez, D.,Martinez-Lozano, P., and Zenobi, R.: Rapid fingerprinting of grape volatile composition using secondary electrospray ionization orbitrap mass spectrometry: A preliminary study of grape ripening, Food Control, 81, 107-112, 2017.

Finlayson-Pitts, B. J. and Pitts, J. N.: Chemistry of the upper and lower atmosphere: theory, experiments, and applications, Academic Press, San Diego, 2000.

Fortner, E. C., Zhao, J., and Zhang, R. Y.: Development of ion driftchemical ionization mass spectrometry, Anal. Chem., 76, 54365440, 2004.

Fujii, T., Selvin, P. C., Sablier, M., and Iwase, K.: Lithium ion attachment mass spectrometry for on-line analysis of trace components in air: direct introduction, Int. J. Mass Spectrom., 209, 39-45, 2001.

Gao, Y. Q., Hall, W. A., and Johnston, M. V.: Molecular composition of monoterpene secondary organic aerosol at low mass loading, Environ. Sci. Technol., 44, 7897-7902, https://doi.org/10.1021/Es101861k, 2010.

Garcia-Gomez, D., Bregy, L., Barrios-Collado, C., Vidal-deMiguel, G., and Zenobi, R.: Real-Time High-Resolution Tandem Mass Spectrometry Identifies Furan Derivatives in Exhaled Breath, Anal. Chem., 87, 6919-6924, https://doi.org/10.1021/acs.analchem.5b01509, 2015.

Garcia-Gomez, D., Gaisl, T., Barrios-Collado, C., Vidal-de-Miguel, G., Kohler, M., and Zenobi, R.: Real-Time Chemical Analysis of E-Cigarette Aerosols By Means Of Secondary Electrospray Ionization Mass Spectrometry, Chem. Eur. J., 22, 2452-2457, 2016.

Garvey, J. F., Herron, W. J., and Vaidyanathan, G.: Probing the Structure and Reactivity of Hydrogen-Bonded Clusters of the Type $\{\mathrm{M}\} n\left\{\mathrm{H}_{2} \mathrm{O}\right\} \mathrm{H}^{+}$, via the Observation of Magic Numbers, Chem. Rev., 94, 1999-2014, https://doi.org/10.1021/Cr00031a011, 1994.

Goldstein, A. H. and Galbally, I. E.: Known and unexplored organic constituents in the earth's atmosphere, Environ. Sci. Technol., 41, 1514-1521, https://doi.org/10.1021/Es072476p, 2007.
Hearn, J. D. and Smith, G. D.: A chemical ionization mass spectrometry method for the online analysis of organic aerosols, Anal. Chem., 76, 2820-2826, 2004.

Hirokawa, J., Kato, T., and Mafune, F.: In situ measurements of atmospheric nitrous acid by chemical ionization mass spectrometry using chloride ion transfer reactions, Anal. Chem., 81, 83808386, 2009.

Horning, E. C., Carroll, D. I., Dzidic, I., Haegele, K. D., Horning, M. G., and Stillwell, R. N.: Liquid Chromatograph Mass Spectrometer-Computer Analytical Systems - ContinuousFlow System Based on Atmospheric-Pressure Ionization MassSpectrometry, J. Chromatogr., 99, 13-21, 1974.

Huey, L. G.: Measurement of trace atmospheric species by chemical ionization mass spectrometry: Speciation of reactive nitrogen and future directions, Mass Spectrom. Rev., 26, 166-184, https://doi.org/10.1002/mas.20118, 2007.

Huey, L. G., Hanson, D. R., and Howard, C. J.: Reactions of $\mathrm{SF}_{6}^{-}$ and $\mathrm{I}^{-}$with Atmospheric Trace Gases, J. Phys. Chem., 99, 50015008, 1995.

Hyttinen, N., Kupiainen-Maatta, O., Rissanen, M. P., Muuronen, M., Ehn, M., and Kurten, T.: Modeling the charging of highly oxidized cyclohexene ozonolysis products using nitratebased chemical ionization, J. Phys. Chem. A, 119, 6339-6345, https://doi.org/10.1021/acs.jpca.5b01818, 2015.

Inomata, S. and Hirokawa, J.: Non-radioactive chemical ionization mass spectrometry using acetic acid-acetate cluster as a reagent ion for the real-time measurement of acids and hydroperoxides, Chem. Lett., 46, 38-41, 2017.

Iyer, S., Lopez-Hilfiker, F., Lee, B. H., Thornton, J. A., and Kurten, T.: Modeling the detection of organic and inorganic compounds using iodide-based chemical ionization, J. Phys. Chem. A, 120, 576-587, https://doi.org/10.1021/acs.jpca.5b09837, 2016.

Jokinen, T., Berndt, T., Makkonen, R., Kerminen, V. M., Junninen, H., Paasonen, P., Stratmann, F., Herrmann, H., Guenther, A. B., Worsnop, D. R., Kulmala, M., Ehn, M., and Sipila, M.: Production of extremely low volatile organic compounds from biogenic emissions: Measured yields and atmospheric implications, P. Natl. Acad. Sci. USA, 112, 7123-7128, 2015.

Junninen, H., Ehn, M., Petäjä, T., Luosujärvi, L., Kotiaho, T., Kostiainen, R., Rohner, U., Gonin, M., Fuhrer, K., Kulmala, M., and Worsnop, D. R.: A high-resolution mass spectrometer to measure atmospheric ion composition, Atmos. Meas. Tech., 3, 10391053, https://doi.org/10.5194/amt-3-1039-2010, 2010.

Kercher, J. P., Riedel, T. P., and Thornton, J. A.: Chlorine activation by $\mathrm{N}_{2} \mathrm{O}_{5}$ : simultaneous, in situ detection of $\mathrm{ClNO}_{2}$ and $\mathrm{N}_{2} \mathrm{O}_{5}$ by chemical ionization mass spectrometry, Atmos. Meas. Tech., 2, 193-204, https://doi.org/10.5194/amt-2-193-2009, 2009.

Kim, M. J., Zoerb, M. C., Campbell, N. R., Zimmermann, K. J., Blomquist, B. W., Huebert, B. J., and Bertram, T. H.: Revisiting benzene cluster cations for the chemical ionization of dimethyl sulfide and select volatile organic compounds, Atmos. Meas. Tech., 9, 1473-1484, https://doi.org/10.5194/amt-9-1473-2016, 2016.

Laskin, A., Laskin, J., and Nizkorodov, S. A.: Mass spectrometric approaches for chemical characterisation of atmospheric aerosols: critical review of the most recent advances, Environ. Chem., 9, 163-189, https://doi.org/10.1071/EN12052, 2012.

Lee, B. H., Lopez-Hilfiker, F. D., Mohr, C., Kurten, T., Worsnop, D. R., and Thornton, J. A.: An Iodide-adduct high-resolution time- 
of-flight chemical-ionization mass spectrometer: Application to atmospheric inorganic and organic compounds, Environ. Sci. Technol., 48, 6309-6317, https://doi.org/10.1021/es500362a, 2014.

Lee, B. H., Mohr, C., Lopez-Hilfiker, F. D., Lutz, A., Hallquist, M., Lee, L., Romer, P., Cohen, R. C., Iyer, S., Kurten, T., Hu, W. W., Day, D. A., Campuzano-Jost, P., Jimenez, J. L., Xu, L., Ng, N. L., Guo, H. Y., Weber, R. J., Wild, R. J., Brown, S. S., Koss, A., de Gouw, J., Olson, K., Goldstein, A. H., Seco, R., Kim, S., McAvey, K., Shepson, P. B., Starn, T., Baumann, K., Edgerton, E. S., Liu, J. M., Shilling, J. E., Miller, D. O., Brune, W., Schobesberger, S., D'Ambro, E. L., and Thornton, J. A.: Highly functionalized organic nitrates in the southeast United States: Contribution to secondary organic aerosol and reactive nitrogen budgets, P. Natl. Acad. Sci. USA, 113, 1516-1521, https://doi.org/10.1073/pnas.1508108113, 2016.

Lopez-Hilfiker, F. D., Mohr, C., Ehn, M., Rubach, F., Kleist, E., Wildt, J., Mentel, Th. F., Lutz, A., Hallquist, M., Worsnop, D., and Thornton, J. A.: A novel method for online analysis of gas and particle composition: description and evaluation of a Filter Inlet for Gases and AEROsols (FIGAERO), Atmos. Meas. Tech., 7, 983-1001, https://doi.org/10.5194/amt-7-983-2014, 2014.

Lopez-Hilfiker, F. D., Mohr, C., Ehn, M., Rubach, F., Kleist, E., Wildt, J., Mentel, Th. F., Carrasquillo, A. J., Daumit, K. E., Hunter, J. F., Kroll, J. H., Worsnop, D. R., and Thornton, J. A.: Phase partitioning and volatility of secondary organic aerosol components formed from a-pinene ozonolysis and $\mathrm{OH}$ oxidation: the importance of accretion products and other low volatility compounds, Atmos. Chem. Phys., 15, 7765-7776, https://doi.org/10.5194/acp-15-7765-2015, 2015.

Lopez-Hilfiker, F. D., Iyer, S., Mohr, C., Lee, B. H., D’Ambro, E. L., Kurtén, T., and Thornton, J. A.: Constraining the sensitivity of iodide adduct chemical ionization mass spectrometry to multifunctional organic molecules using the collision limit and thermodynamic stability of iodide ion adducts, Atmos. Meas. Tech., 9, 1505-1512, https://doi.org/10.5194/amt-9-1505-2016, 2016a.

Lopez-Hilfiker, F. D., Mohr, C., D’Ambro, E. L., Lutz, A., Riedel, T. P., Gaston, C. J., Iyer, S., Zhang, Z., Gold, A., Surratt, J. D., Lee, B. H., Kurten, T., Hu, W. W., Jimenez, J., Hallquist, M., and Thornton, J. A.: Molecular Composition and Volatility of Organic Aerosol in the Southeastern US: Implications for IEPOX Derived SOA, Environ. Sci. Technol., 50, 2200-2209, https://doi.org/10.1021/acs.est.5b04769, 2016b.

Martinez-Lozano, P., Zingaro, L., Finiguerra, A., and Cristoni, S.: Secondary electrospray ionization-mass spectrometry: breath study on a control group, J. Breath Res., 5, 016002, https://doi.org/10.1088/1752-7155/5/1/016002, 2011.

Meier, L., Berchtold, C., Schmid, S., and Zenobi, R.: Sensitive detection of drug vapors using an ion funnel interface for secondary electrospray ionization mass spectrometry, J. Mass Spectrom., 47, 555-559, https://doi.org/10.1002/jms.2982, 2012.

Mohr, C., Lopez-Hilfiker, F. D., Yli-Juuti, T., Heitto, A., Lutz, A., Hallquist, M., D’Ambro, E. L., Rissanen, M. P., Hao, L. Q., Schobesberger, S., Kulmala, M., Mauldin III, R. L., Makkonen, U., Sipilä, M., Petäjä, T., and Thornton, J. A.: Ambient observations of dimers from terpene oxidation in the gas-phase: implications for new particle formation and growth, Geophys. Res. Lett., 44, 2958-2966, https://doi.org/10.1002/2017GL072718, 2017.
Nguyen, T. B., Bateman, A. P., Bones, D. L., Nizkorodov, S. A., Laskin, J., and Laskin, A.: High-resolution mass spectrometry analysis of secondary organic aerosol generated by ozonolysis of isoprene, Atmos. Environ., 44, 1032-1042, 2010.

Nizkorodov, S. A., Laskin, J., and Laskin, A.: Molecular chemistry of organic aerosols through the application of high resolution mass spectrometry, Phys. Chem. Chem. Phys., 13, 3612-3629, https://doi.org/10.1039/c0cp02032j, 2011.

Nowak, J. B., Huey, L. G., Eisele, F. L., Tanner, D. J., Mauldin, R. L., Cantrell, C., Kosciuch, E., and Davis, D. D.: Chemical ionization mass spectrometry technique for detection of dimethylsulfoxide and ammonia, J. Geophys. Res., 107, 4363, https://doi.org/10.1029/2001jd001058, 2002.

Noziere, B., Kaberer, M., Claeys, M., Allan, J., D’Anna, B., Decesari, S., Finessi, E., Glasius, M., Grgic, I., Hamilton, J. F., Hoffmann, T., Iinuma, Y., Jaoui, M., Kahno, A., Kampf, C. J., Kourtchev, I., Maenhaut, W., Marsden, N., Saarikoski, S., Schnelle-Kreis, J., Surratt, J. D., Szidat, S., Szmigielski, R., and Wisthaler, A.: The Molecular Identification of Organic Compounds in the Atmosphere: State of the Art and Challenges, Chem. Rev., 115, 3919-3983, https://doi.org/10.1021/cr5003485, 2015.

Praplan, A. P., Schobesberger, S., Bianchi, F., Rissanen, M. P., Ehn, M., Jokinen, T., Junninen, H., Adamov, A., Amorim, A., Dommen, J., Duplissy, J., Hakala, J., Hansel, A., Heinritzi, M., Kangasluoma, J., Kirkby, J., Krapf, M., Kürten, A., Lehtipalo, K., Riccobono, F., Rondo, L., Sarnela, N., Simon, M., Tomé, A., Tröstl, J., Winkler, P. M., Williamson, C., Ye, P., Curtius, J., Baltensperger, U., Donahue, N. M., Kulmala, M., and Worsnop, D. R.: Elemental composition and clustering behaviour of apinene oxidation products for different oxidation conditions, Atmos. Chem. Phys., 15, 4145-4159, https://doi.org/10.5194/acp15-4145-2015, 2015.

Seinfeld, J. H. and Pandis, S. N.: Atmospheric chemistry and physics: from air pollution to climate change, 2nd Edn., Wiley, Hoboken, NJ, USA, 2006.

Smith, J. N., Moore, K. F., McMurry, P. H., and Eisele, F. L.: Atmospheric measurements of sub-20 nm diameter particle chemical composition by thermal desorption chemical ionization mass spectrometry, Aerosol Sci. Technol., 38, 100-110, https://doi.org/10.1080/02786820490249036, 2004.

Tam, M. and Hill, H. H.: Secondary electrospray ionization-ion mobility spectrometry for explosive vapor detection, Anal. Chem., 76, 2741-2747, https://doi.org/10.1021/ac0354591, 2004.

Tu, P. J., Hall, W. A., and Johnston, M. V.: Characterization of Highly Oxidized Molecules in Fresh and Aged Biogenic Secondary Organic Aerosol, Anal. Chem., 88, 4495-4501, 2016.

Veres, P., Roberts, J. M., Warneke, C., Welsh-Bon, D., Zahniser, M., Herndon, S., Fall, R., and de Gouw, J.: Development of negativeion proton-transfer chemical-ionization mass spectrometry (NIPT-CIMS) for the measurement of gas-phase organic acids in the atmosphere, Int. J. Mass Spectrom., 274, 48-55, 2008.

Whitehouse, C. M., Levin, F., Meng, C. K., and Fenn, J. B.: Proceedings of the 34th ASMS Conference on Mass Spectrometry and Allied Topics, Denver, No. 507, 1986.

Witkowski, B. and Gierczak, T.: Analysis of alphaacyloxyhydroperoxy aldehydes with electrospray ionizationtandem mass spectrometry (ESI-MS ${ }^{n}$ ), J. Mass Spectrom., 48, 79-88, https://doi.org/10.1002/jms.3130, 2013. 
Wu, C., Siems, W. F., and Hill, H. H.: Secondary electrospray ionization ion mobility spectrometry/mass spectrometry of illicit drugs, Anal. Chem., 72, 396-403, https://doi.org/10.1021/Ac9907235, 2000.

Yatavelli, R. L. N., Lopez-Hilfiker, F., Wargo, J. D., Kimmel, J. R., Cubison, M. J., Bertram, T. H., Jimenez, J. L., Gonin, M., Worsnop, D. R., and Thornton, J. A.: A Chemical Ionization High-Resolution Time-of-Flight Mass Spectrometer Coupled to a Micro Orifice Volatilization Impactor (MOVI-HRToF-CIMS) for Analysis of Gas and ParticlePhase Organic Species, Aerosol Sci. Technol., 46, 1313-1327, https://doi.org/10.1080/02786826.2012.712236, 2012.

Yuan, B., Koss, A., Warneke, C., Gilman, J. B., Lerner, B. M., Stark, H., and de Gouw, J. A.: A high-resolution time-of-flight chemical ionization mass spectrometer utilizing hydronium ions $\left(\mathrm{H}_{3} \mathrm{O}^{+}\right.$ToF-CIMS $)$for measurements of volatile organic compounds in the atmosphere, Atmos. Meas. Tech., 9, 2735-2752, https://doi.org/10.5194/amt-9-2735-2016, 2016.

Zhang, X., Lambe, A. T., Upshur, M. A., Brooks, W. A., Gray Be, A., Thomson, R. J., Geiger, F. M., Surratt, J. D., Zhang, Z., Gold, A., Graf, S., Cubison, M. J., Groessl, M., Jayne, J. T., Worsnop, D. R., and Canagaratna, M. R.: Highly Oxygenated Multifunctional Compounds in $\alpha$-Pinene Secondary Organic Aerosol, Environ. Sci. Technol., 51, 59325940, https://doi.org/10.1021/acs.est.6b06588, 2017.
Zhao, J., Eisele, F. L., Titcombe, M., Kuang, C. G., and McMurry, P. H.: Chemical ionization mass spectrometric measurements of atmospheric neutral clusters using the cluster-CIMS, J. Geophys. Res., 115, D08205, https://doi.org/10.1029/2009JD012606, 2010.

Zhao, Y., Wingen, L. M., Perraud, V., Greaves, J., and FinlaysonPitts, B. J.: Role of the reaction of stabilized Criegee intermediates with peroxy radicals in particle formation and growth in air, Phys. Chem. Chem. Phys., 17, 12500-12514, https://doi.org/10.1039/C5cp01171j, 2015.

Zhao, Y., Wingen, L. M., Perraud, V., and Finlayson-Pitts, B. J.: Phase, composition, and growth mechanism for secondary organic aerosol from the ozonolysis of $\alpha$-cedrene, Atmos. Chem. Phys., 16, 3245-3264, https://doi.org/10.5194/acp-163245-2016, 2016.

Zhu, J. J., Bean, H. D., Kuo, Y. M., and Hill, J. E.: Fast Detection of Volatile Organic Compounds from Bacterial Cultures by Secondary Electrospray Ionization-Mass Spectrometry, J. Clin. Microbiol., 48, 4426-4431, https://doi.org/10.1128/Jcm.00392-10, 2010 . 